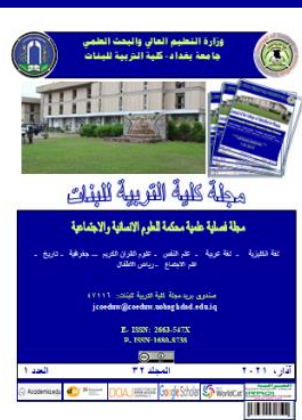

مبالة كلية التربية لابنات

مجلة فصلية علمية همكمة في العلوم الانسانية والاجتماعية ثصدرها كلية التربية لبنات-

\title{
هامعة بغداد-العراق
}

Journal of the College of Education for Women

A Refereed Scientific Quarterly Journal for Human and Social Sciences Issued by the College of Education for Women-University of Baghdad-IRAQ

Received: January 25, 2021

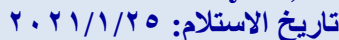

Accepted: February 14, 2021

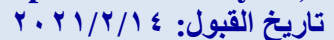

Published: March 28, 2021

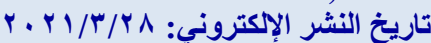

DOI: http://doi.org/ 10.36231/coedw.v32i1.1469

\section{Judicial Legislations and the Tribal Claims System in the Royal Period: A Documentary Study}

\section{Ahmed Abdul Wahid Abdul Nabi}

Center for Reviving the Arab Scientific

Heritage/ University of Baghdad ahmedalhelfe@yahoo.com

\begin{abstract}
The present research tackles a number of historical facts and incidents with a purely legal dimension in an important stage in the contemporary history of Iraq, especially the era of the British occupation. This resulted in innumerable social, political and legal problems, particularily the judicial legislation problems in Iraq. These legislations included a set of civil laws and in force governmental procedures that will be discussed historically by examining documents issued by the Ministries of Justice and Interior Affairs in the governments of monarchy for the period from 1921-to1958. The data of the present paper relied on the Iraqi Library and Archives, (hence DKW). The study adopted the narrative historical methodology when investigating the judicial legislations in the royal era from 1921-to1958. The scale adopted was the contemporary measurement and evaluation in the Iraqi contemporary history. Finally, the results revealed that the history of the penal procedures in the royal era was those multiple attempts to reconcile between the two types of penal procedures that represent the history of the relationship between the individual and the state. Such legislations were set according to the circumstances of each country and to the level of its intellectual, social, political and human development to serve primarily the interests of the British occupation, and fulfill the desires of the influential class in the royal era. Because these legislations and laws were not based on modern scientific theories, many people were wronged, including the judicial authority and legal clerks who complained from their implementation and their continual application on Iraq for all this period.
\end{abstract}

Keywords: Iraq, judgment, legislation, monarchy

$$
\begin{aligned}
& \text { التشريعات العدلية ونظام دعاوى العشائر في العها } \\
& \text { الملكي: دراسة وثائقية }
\end{aligned}
$$

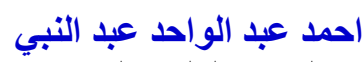

$$
\begin{aligned}
& \text { مركز إحياء التراث العلمي العربي/ جامعة بغداد } \\
& \text { ahmedalhelfe@yahoo.com }
\end{aligned}
$$

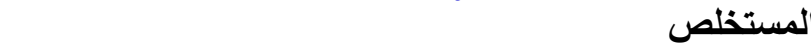

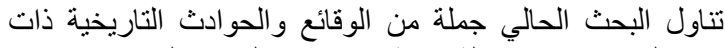

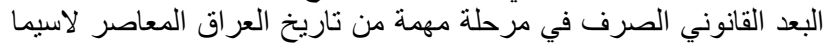

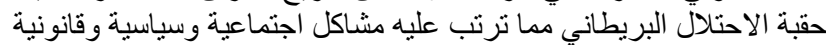

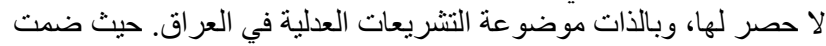

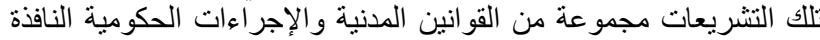

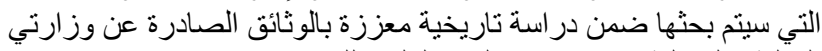

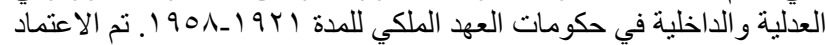

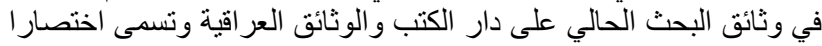

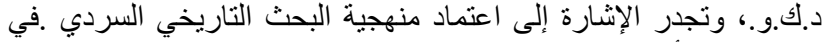

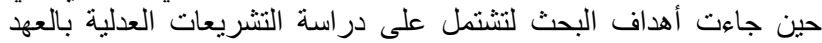

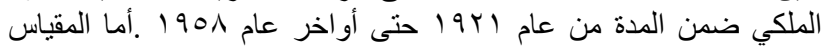

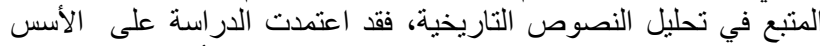

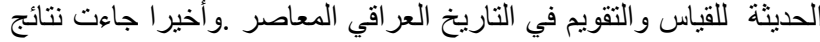

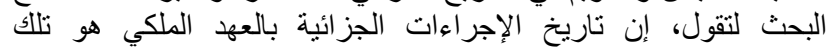

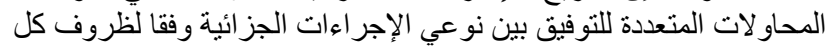

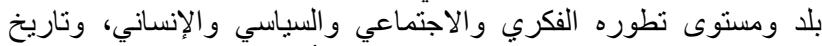

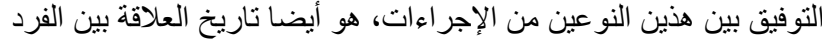

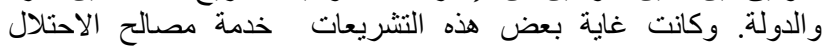

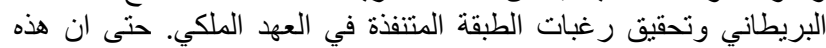

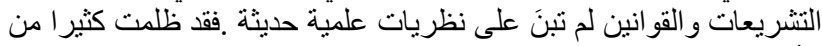

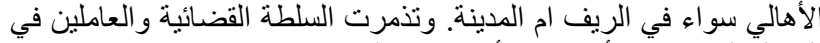
المجال القانوني في أثناء ثنفيذ أحكام هذه القو انين .

$$
\text { الكلمات المفتاحية: تشريعات، الحكم، العراق، الملكي }
$$




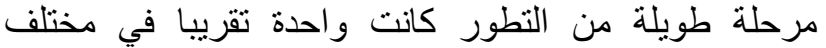

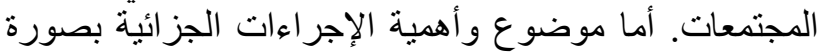

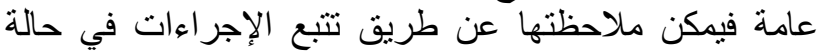

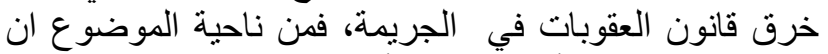

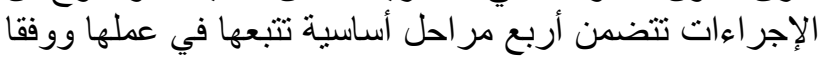

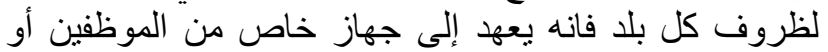

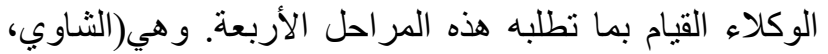

:( ) $19 \mathrm{VY}$

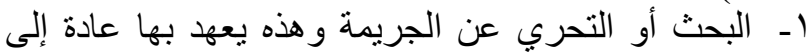
الثرطة وفي بعض الدول إلى شرطة خاصة يطلق علئ عليها اسم (الثرطة القضائية) كما في فرنسا وبعض الترط الدولة فاصة التي

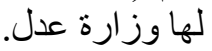
r- هي مرحلة تعقيب المتهم وتحريك الدعوى ضده وهذه

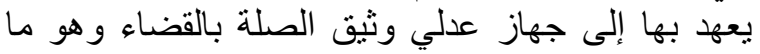

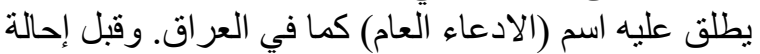

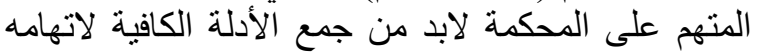
بارتكاب الجريمة، فالمسالة تتعلق باتخاذ قرار لإلة لإحالة المتهم على المحكمة.

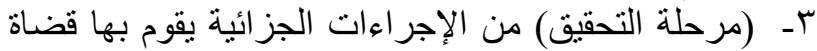

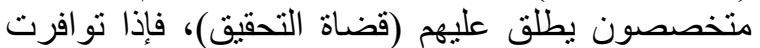

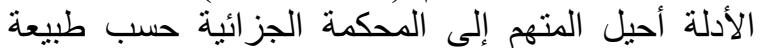

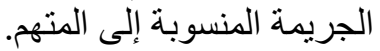

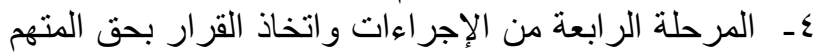

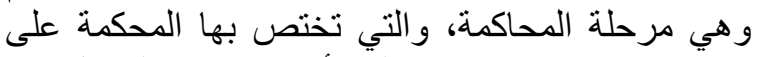

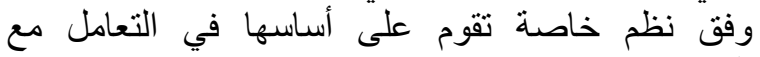

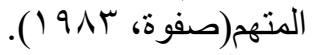

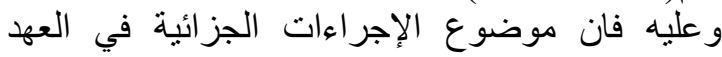

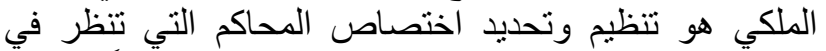

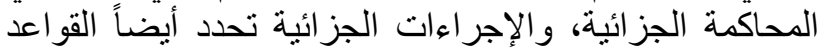

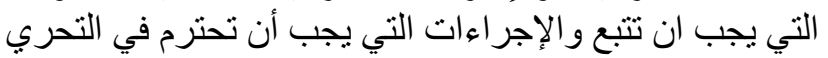

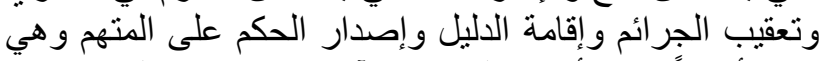

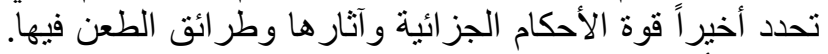

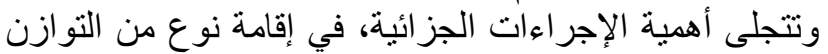

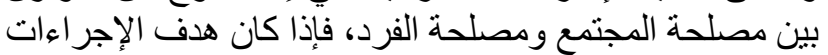

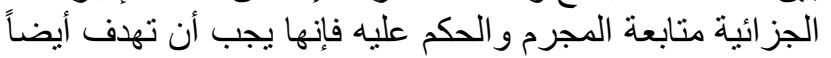

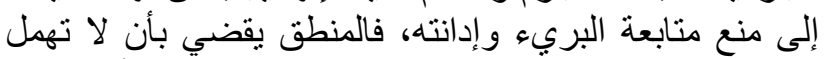

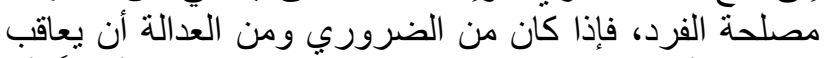

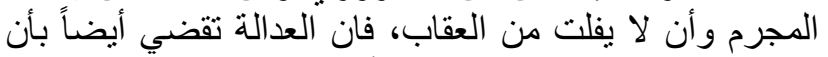

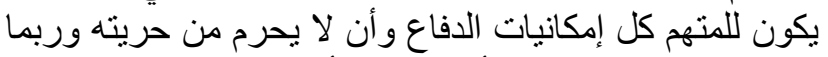

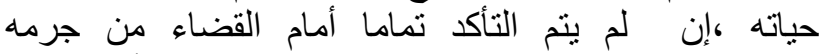

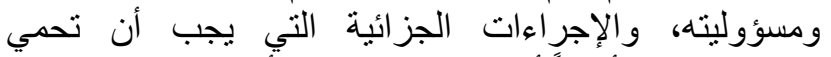

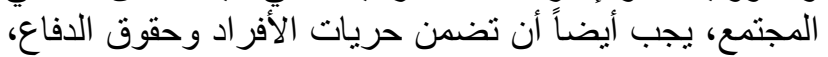

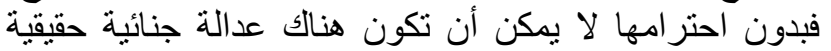

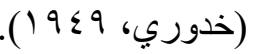
يمكن القول: إن تاريخ الإجراءات الجزائية بالعهد

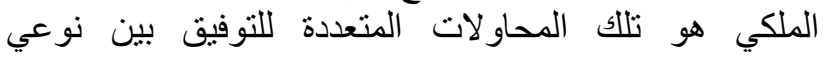

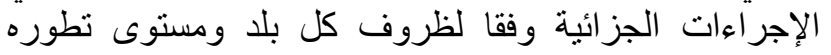
الفكري والاجتماعي والجزائي والسياسي والإنساني، وتاريخ التوفيق بين نطورن

\section{1. مقدمة عن الأصول و الإجراءات الجزائية}

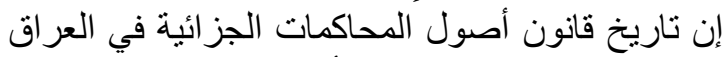

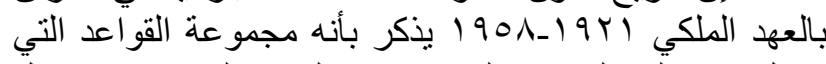

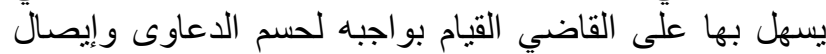
الحق لصاحبه وتحقيق العدالة فهو يهنم بتحديد الطريقة أو الوبائ

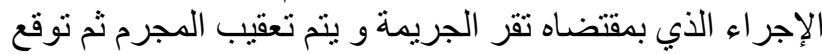

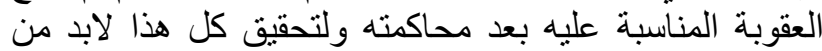

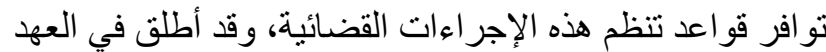

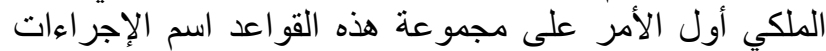

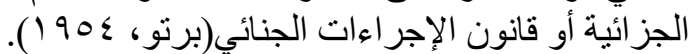

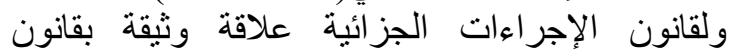

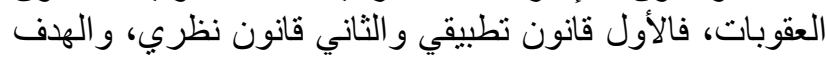

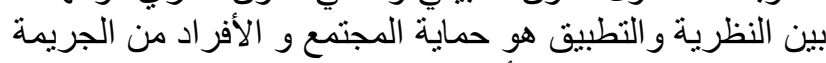

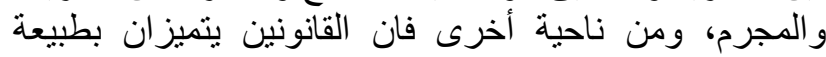

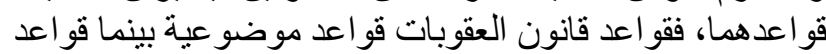

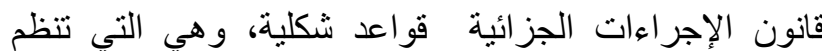

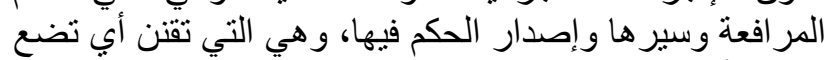

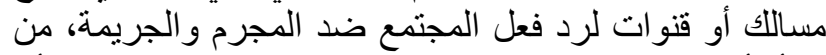

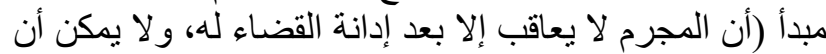

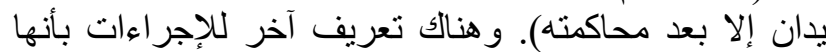

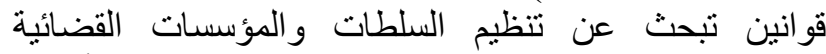
الجزائية، وتعيين اختصاصها وتحديد التيدي سير القضية من أعمال التحري والتحقيق ودين الخحاكمة حتى تنفيذ الحكم، و والغاية منها

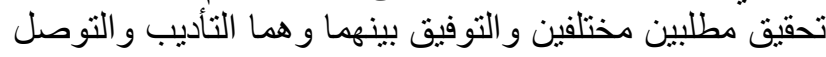

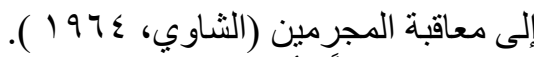

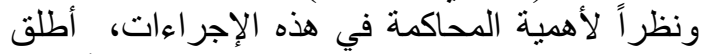

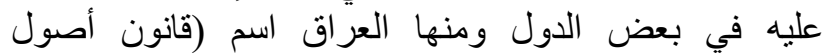
المحاكمات الجزائية) وفي دول أخرى أطلق عليه اسم (قانون

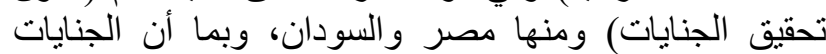

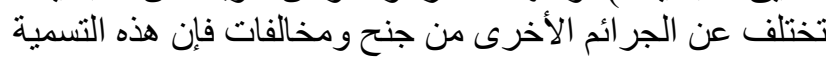

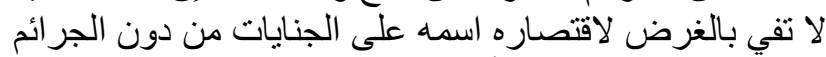

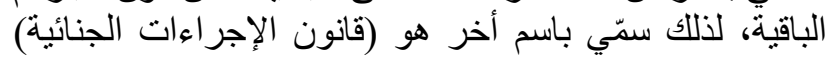

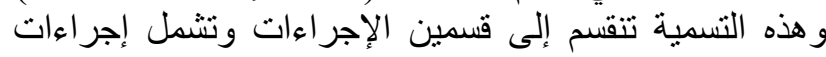

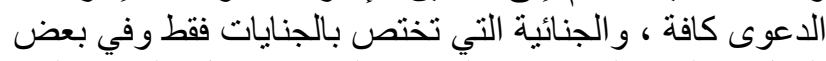

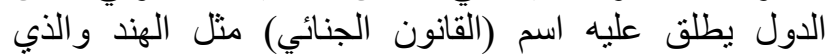

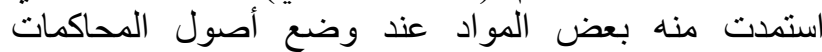
الجزائية البغدادي، الذي يختص بالإجراءات الجناء الدائية أيضا،

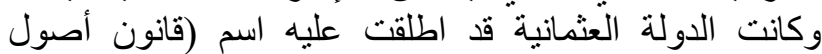

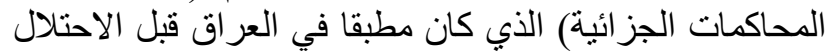

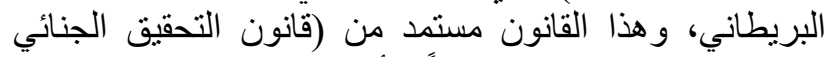
الفرنسي) الذي كان مصدراً لأكثر قوانين الدون الدول العربية الجنية

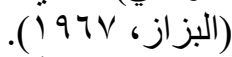

وبما أن البريطانيين قد أسهووا في وضع الأنع القانون

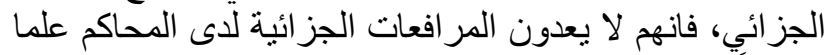

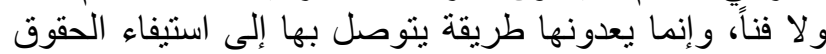

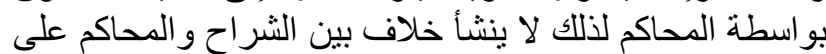

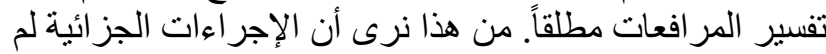

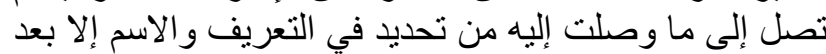


العربية محل المصطلحات التي لم يصبها التوفيق في الترجمة السابقة(د. ك. و.، أنظمة وقو انين ومنانثير ،

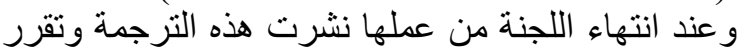

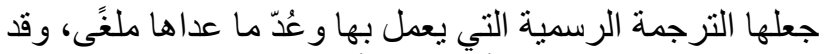

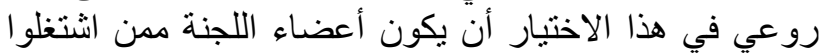

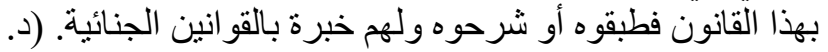

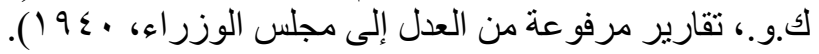

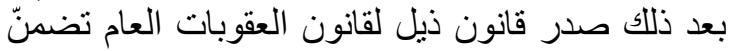

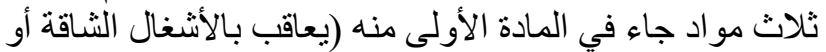

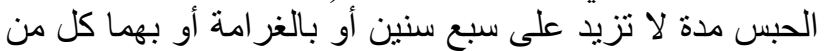

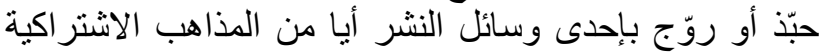

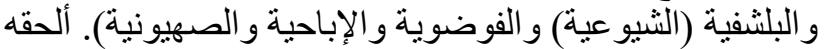

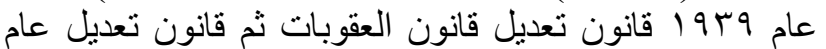

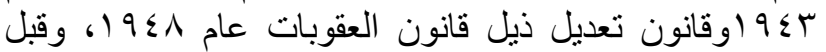

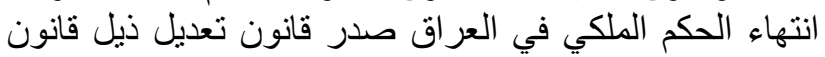

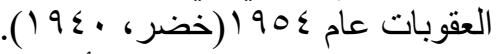

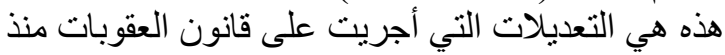

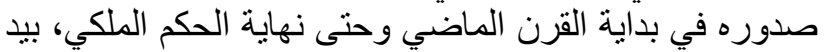

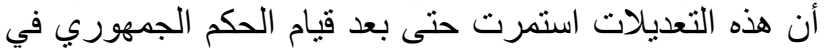

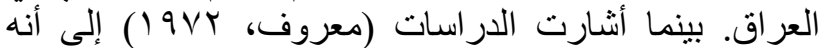

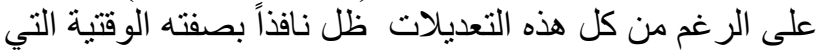

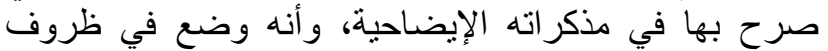

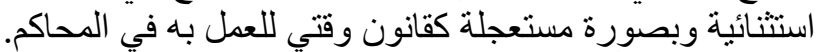

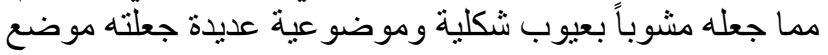
انتقاد وتذمر من العاملين في المجال القانوني و غيرهاتهم (البزاز،

(197V

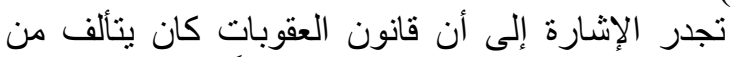

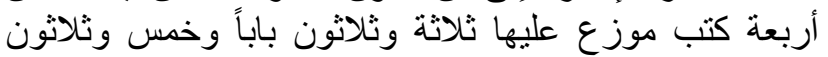

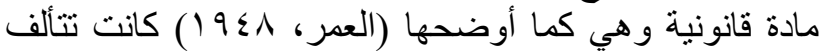

الكتاب الأول: تضمن الأحكام العامة التي تسري على جميع

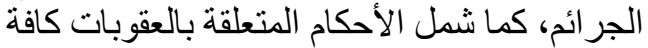

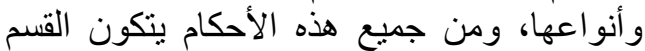
العام لقانون العقوبات.

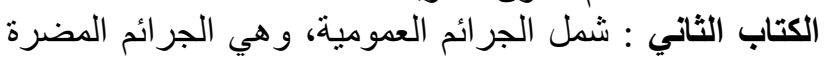

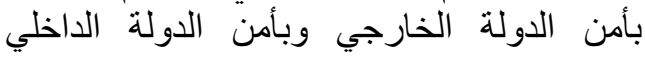

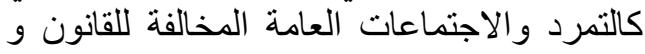

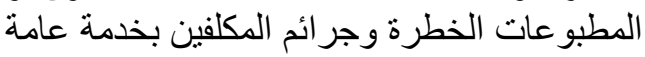
كالرشوة والاختلاس و إساءة الموظفين التوات الستعمال

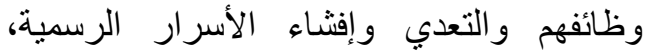
والجرائم التي ولتئي ترتكب ضد السلطة العامة

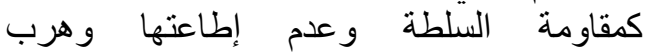

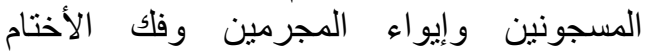

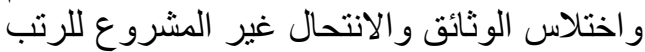

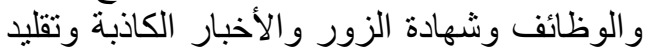

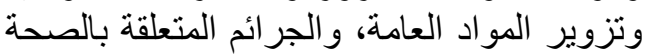

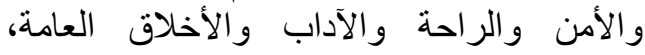

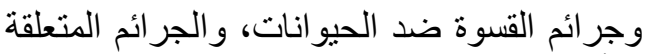

هذين النوعين من الإجر اءات، هو أيضا تاريخ العلاقة بين الفرد

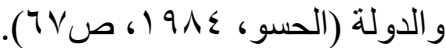

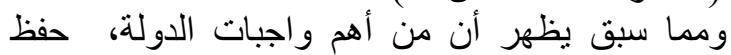

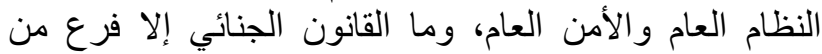

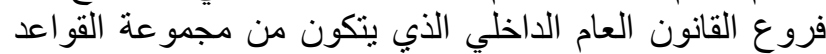

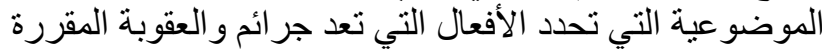

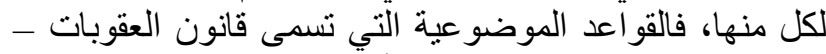

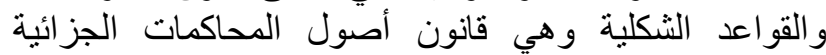
تدخلان في نطاق دائرة القانون العام الذي يقسم القانون الجنان الجنائي

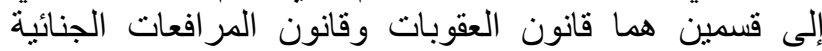

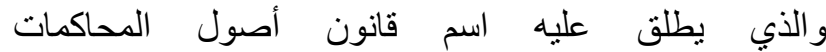

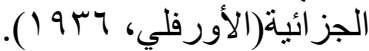

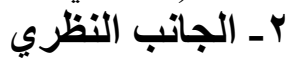

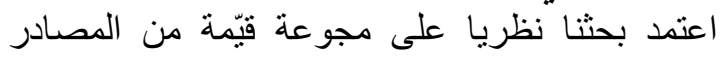

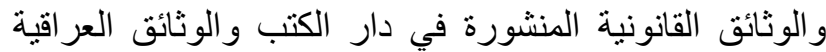

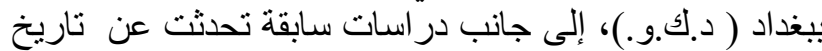

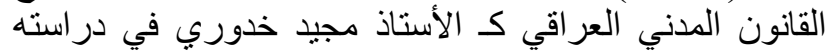

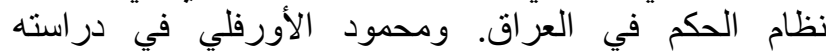

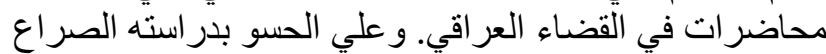
على السلطة في العر اق الملكي و غير هير العـا.

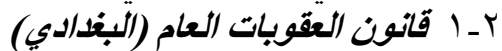

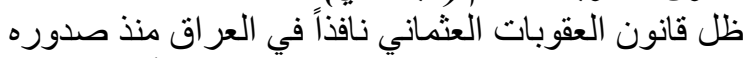

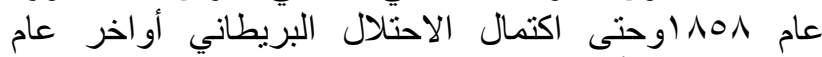

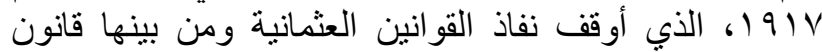

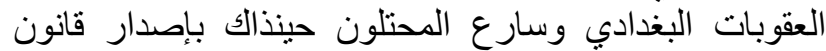

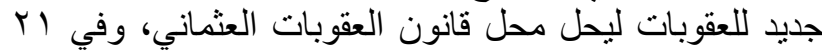

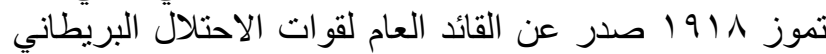

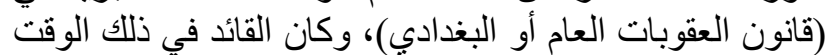

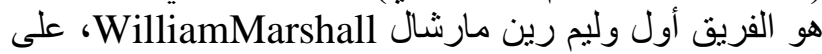

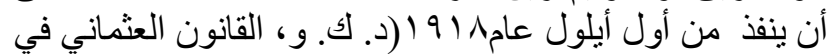

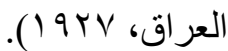
وضع قانون العقوبات أول مرة باللغة الإنجليزية

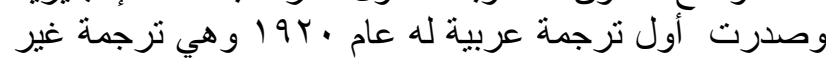

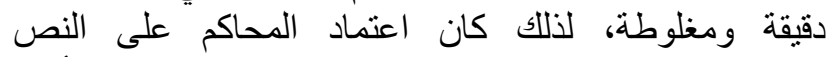
الإنجليزي و هو النص الرسمي لهذا القانون وبقي العمل بهان أكثر الثران

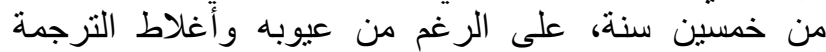

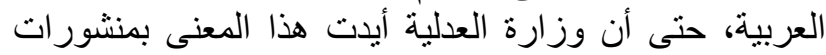

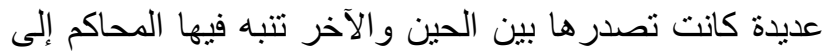

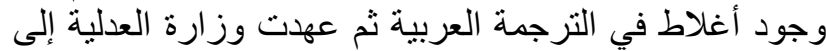
تأليف لجنة ترأسها مصطفى كامل (أستاذ القانون العام بكلية التبليتي

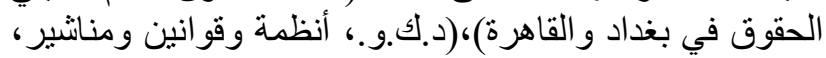

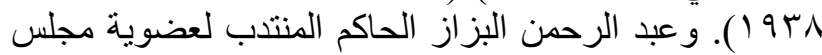

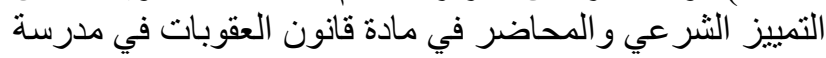

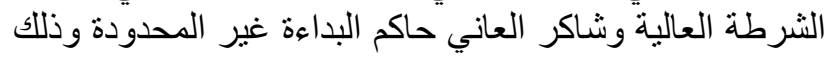

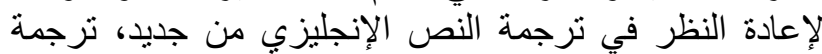
صحيحة يستقيم معها العمل بالقانون، وقد الإند حاولت الترن اللجنة الآتيان

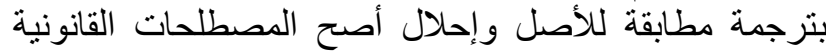


صلاحية محقق وتخويله سلطة التحري في المساكن وإصدار

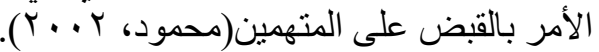

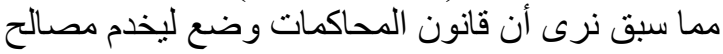

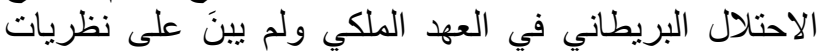

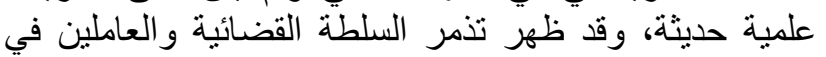

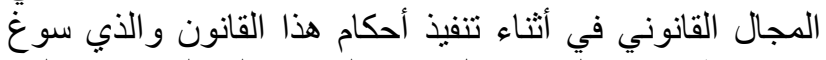

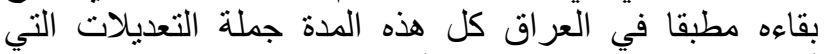

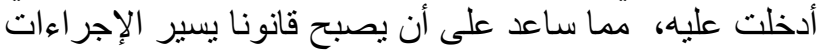

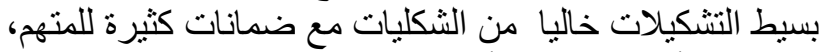

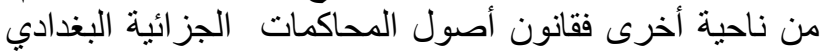

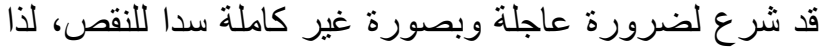

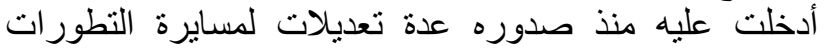
و التغيرات الحاصلة في المجتمع، ومن هذه التهات التعديلات، التعديل

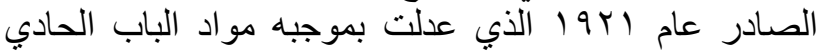

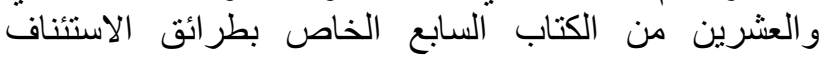

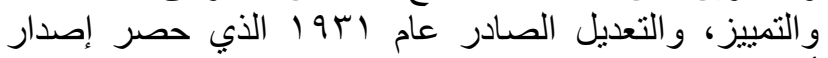
أوامر القبض والتحري بالقضاة فقط واستعمل كلمة (محقق)

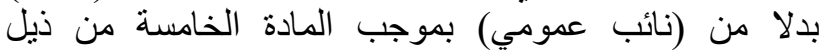

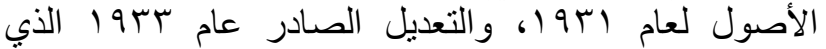

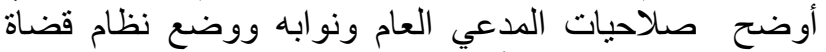

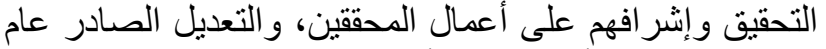

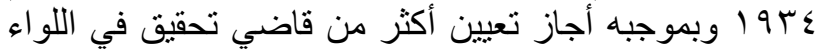

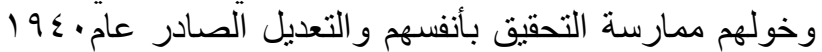

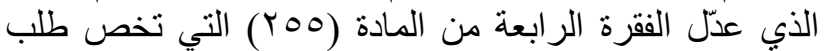

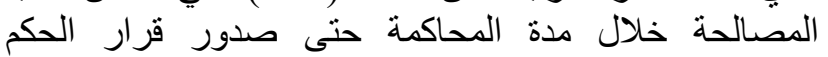

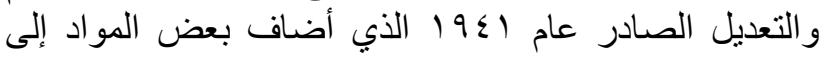

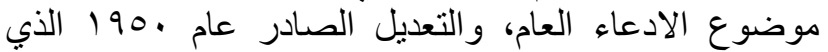

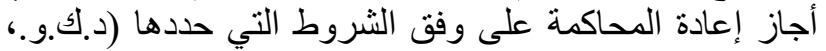

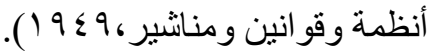

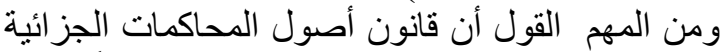

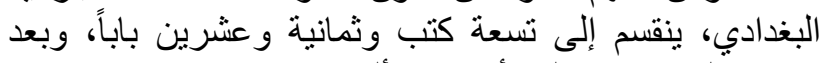

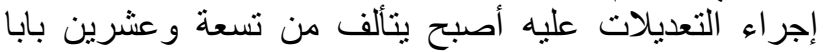

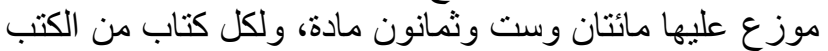

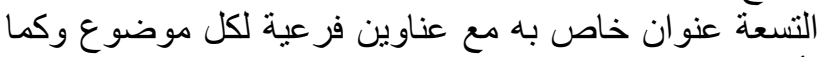

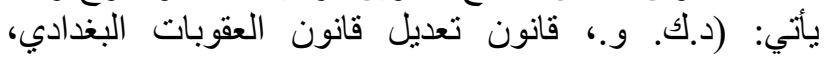

(190.

الكتاب الأول يتعلق بتطبيق القانون وبعض التعريفات ومنها:

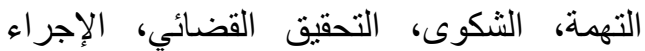
القضائي، ضابط منوط بنقطة بولئيس ضابط لإنط بوليس حاكم سياسي، حاكم مدني، نائب عمو مئي.

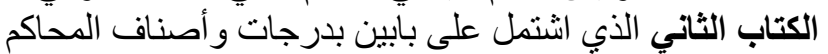
الجز ائية وسلطة المحققين، وقيسّم المحاكم الجز ائية الئية

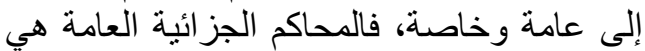

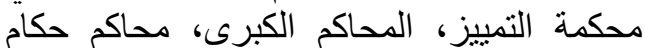
الدرجة الأولى، محاكم حكام الدرجة الدامئ الثانية، محاكم حكام الدرجة الثالثة، أما الدحاكم الجزائية الألية

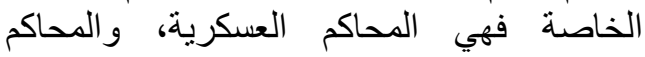
العشائرية، ومحاكمات مدير الثرطة ومعاونة الثرانه لأفراد الثرطة ومنح سلطة المحاكم وماهية

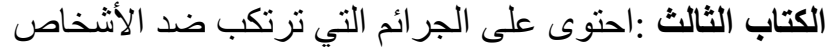

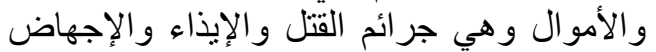

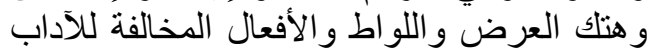

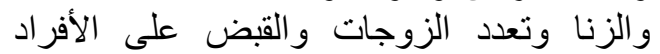
وحبسه بدون حق و الخطف والإن والإرهاب و التهديد الافراد

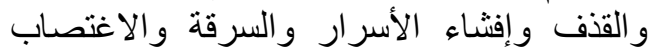

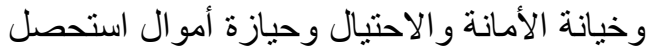
عليها بطريقة غير مشرو عة والتزوير و الموازين

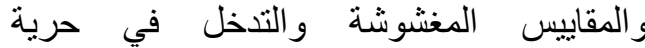

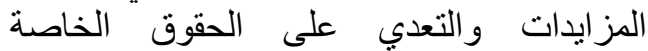
و التصرف بطريق الغش والإلفالفيلاس بالتدليس و الإخلال الجنائي بعقود الخدمة والحريق والإن عمدا

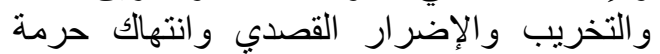

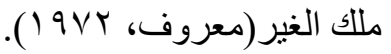

الكتاب الرابع: فضم المخالفات المتعلقة بالطرائق العامة

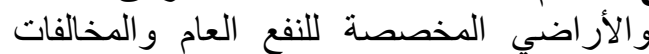
المتعلقة بالأمن والسلامة العامة والآداب العامة الامة

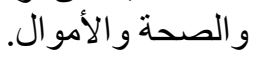

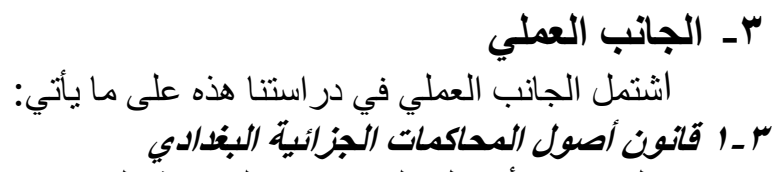

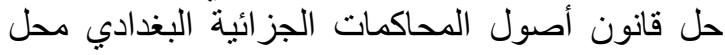

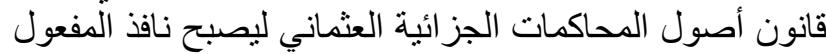

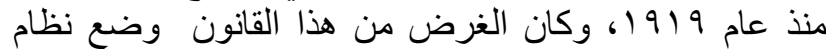

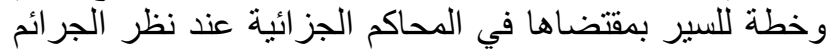

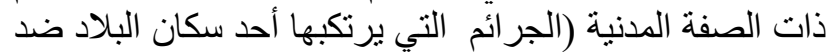

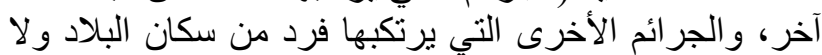

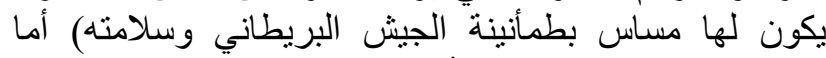

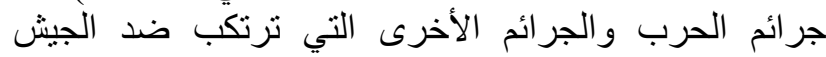

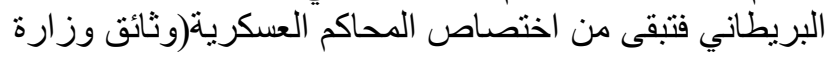

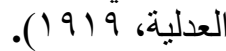

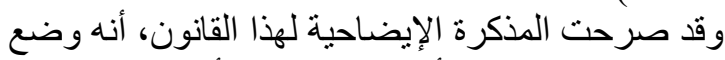

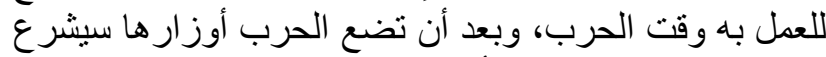

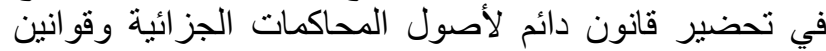

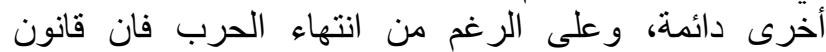

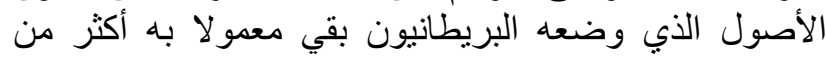

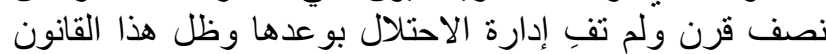

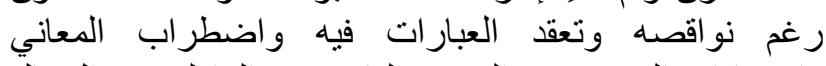

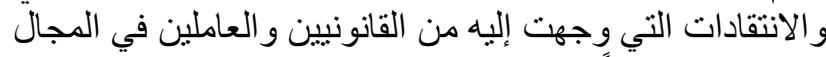

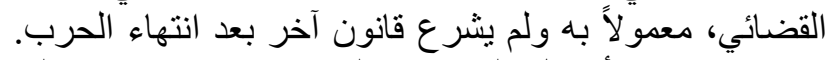

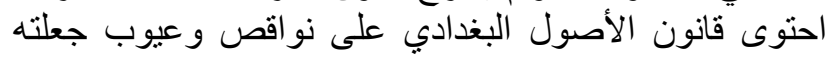

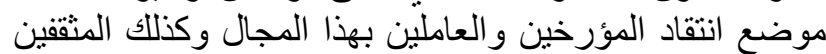

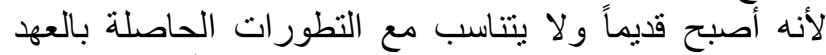

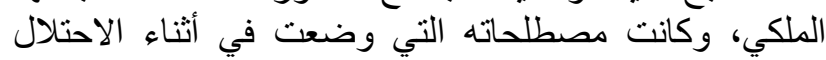

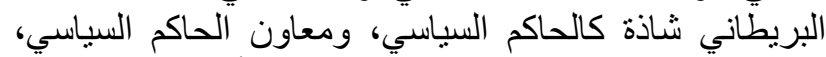

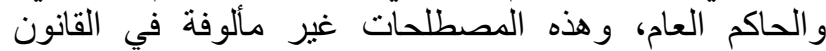
الجنائي، فضلا عن أحكامه الغريبة، كمنح ضابط الثرطة 
إيقاف تتفيذ الأحكام والإعفاء عنها، وسلطة محكمة التمبيز في تبديل العقوبات.

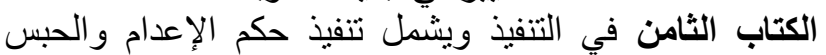

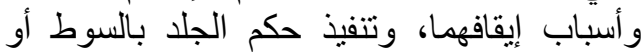

بالمقر عة، و أسباب إيقافهما.

الكتاب التاسع هو ملحق في الأحكام السابقة بالبراءة والمة والإدانة

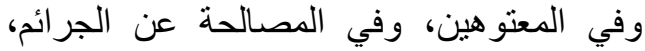

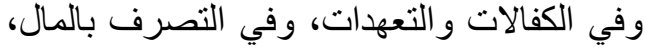

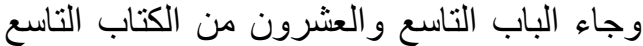

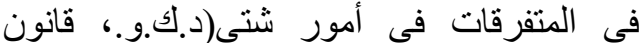

تعديل قانون العقوبات البخدادي).

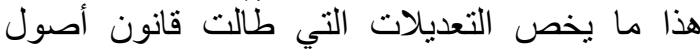

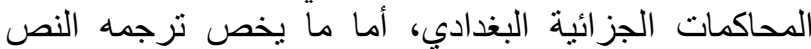

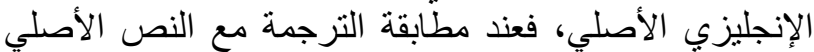

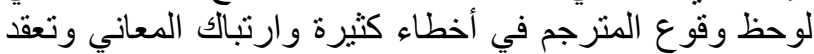

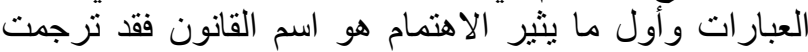
العبارة الآتية ( These regulations may be called the (Baghdadi Criminal Procedural Regulations الصيغة الآتية: (يطلق على هذه الانظمة اسم قانون أصول

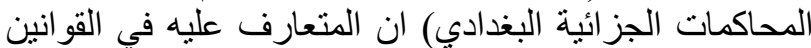

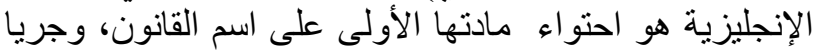
على هذه القاعدة ذكرت هذه المادة ومن الغريب في الأمر قوله لهانه

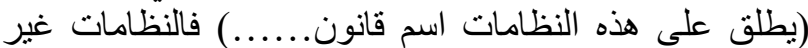

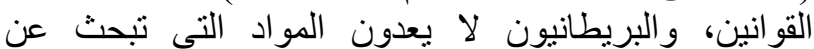
المر افعات قانوناً بل قو اعد وأنظمة وينركون لانئن تفصيلها للمحاكم

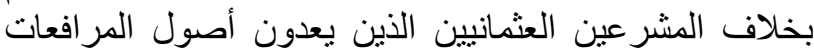

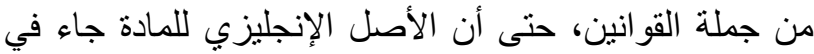

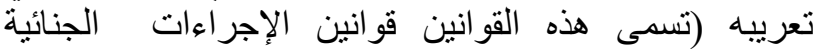

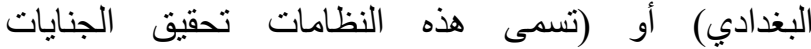

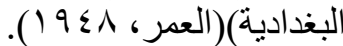

و الظاهر أن المترجم أر اد أن يعيد إلى الأذهان كلمة القانون التي كانت معروفة في ذللك الوقت الت باصنت التطلاحها العثماني، و عند الاحتلال البريطاني أخذت الإدارة الباني البريطانية

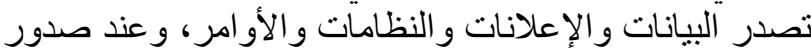

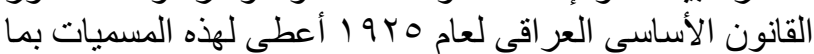

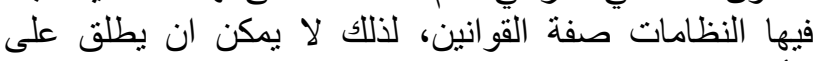

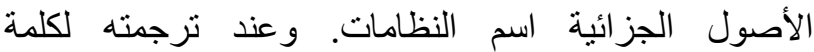
(Investigation)

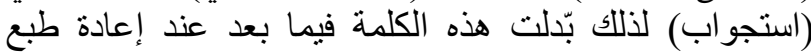

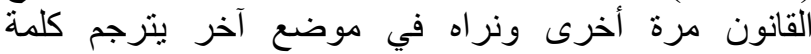
(Inquiry)

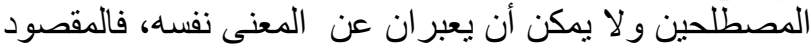

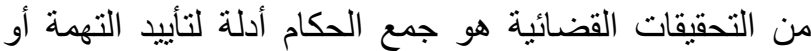

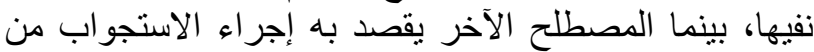

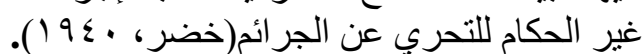

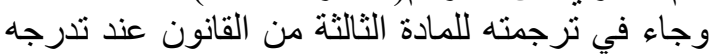

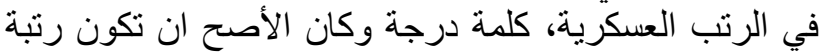

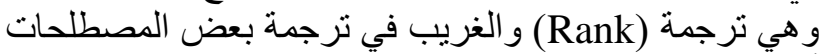

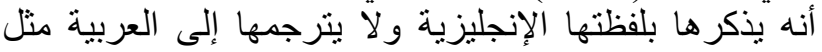

الأحكام التي تصدر ها، وحدد صلاحية المحاكم حسب درجأتها، فاختصت محاكم الدرجة الأولى هاتى

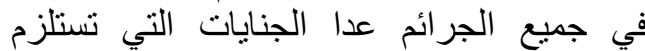

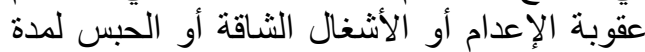
تزيد عن سبع سنوات، وتحكم محاكم الدرجة الأنة

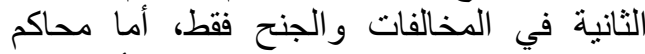
الدرجة الثالثة فتحكم في المخالفات فقط، أما سلطة

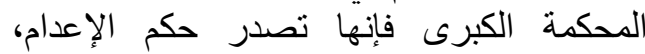

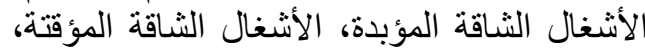

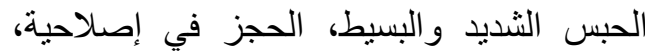

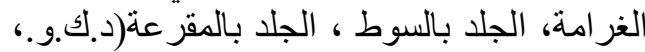

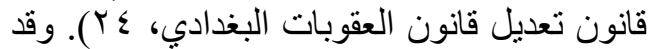
أوضح الباب الثالث من الكتاب الثاني ما يتعلق في التي المحققين و علاقتهم بحكام الجزاء الب وبحكام التحقيق التيق

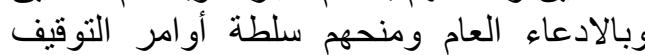

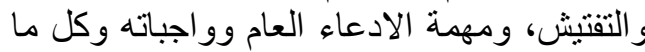
يتعلق في هذه الوظبفة.

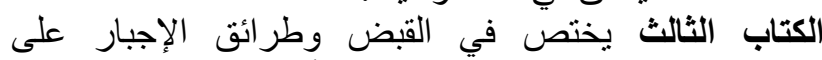

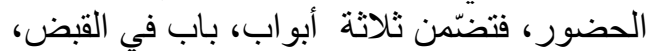

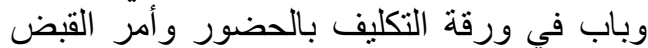

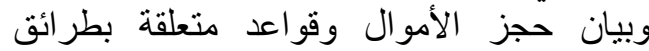
الإجبار على الحضور، وباب في التكليف بتقديم

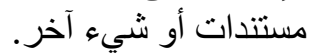

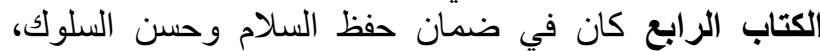

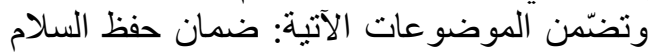

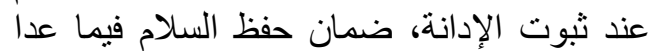

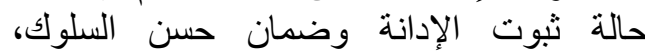

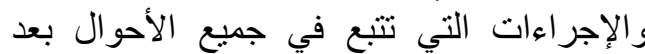

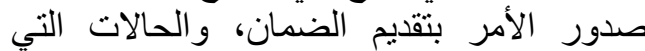

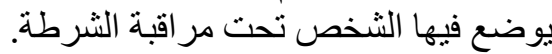

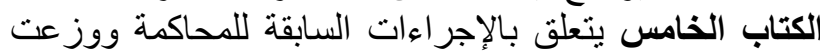

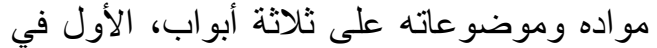

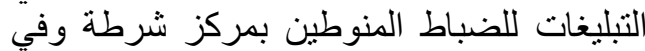

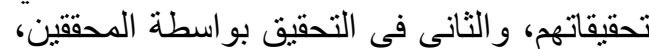
و الثالث في الإحالة على محكمة كبرى في للمحاكمة.

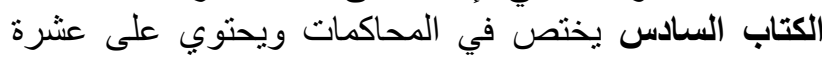

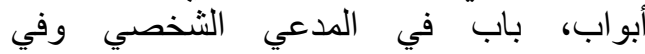

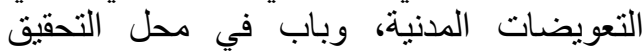
القضائي و المحاكمة، وباب في المأذونية المباب اللازمة

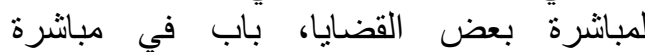

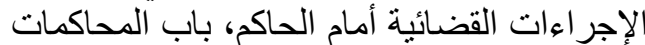

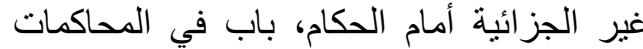

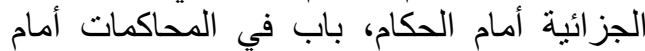

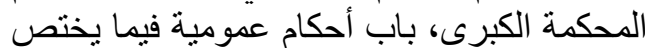

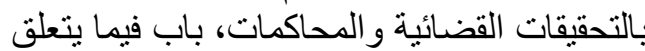

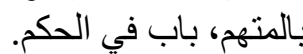

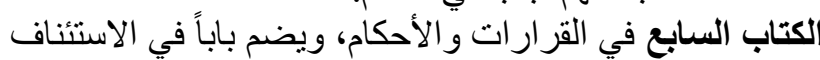

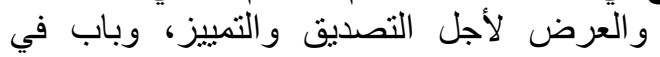


القو انين قد حلت محلها قو انين أخرى، فجعلت مهمة دارس

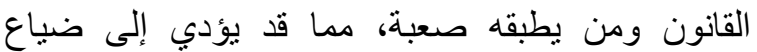

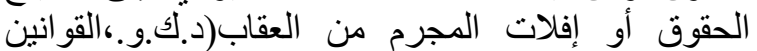

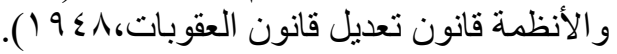

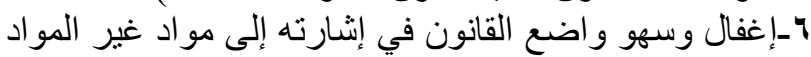

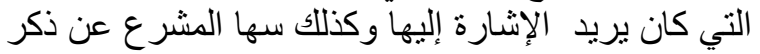

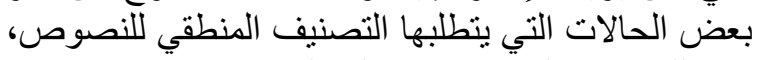

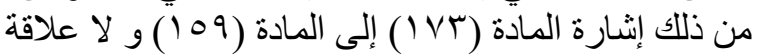

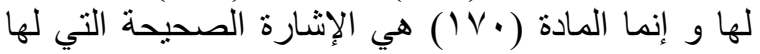

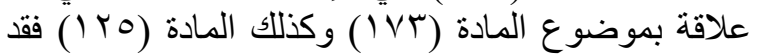

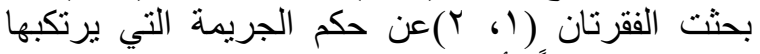

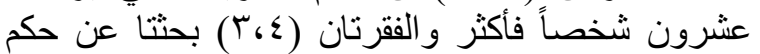

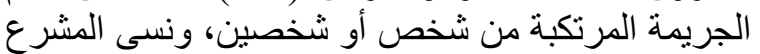

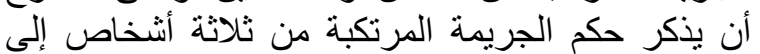

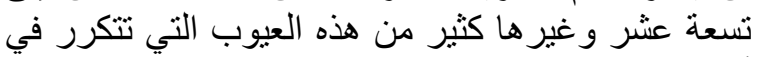

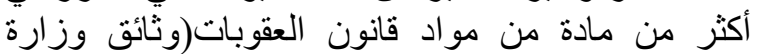
العدلية، ع ع 190 1).

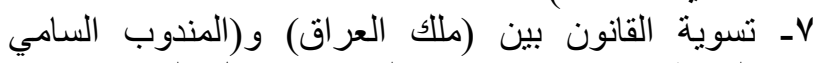
البريطاني) في كثير من المواد إذ جعل إن الدين العقوبة واحدة

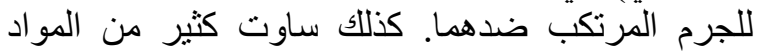
القانونية بين القوات العسكرية العر اقية و القوات التير المسلحة

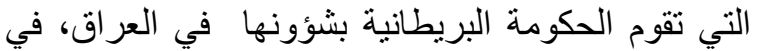

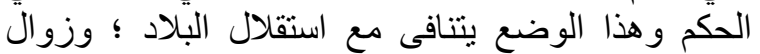

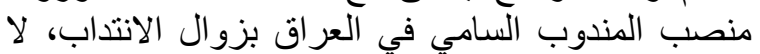

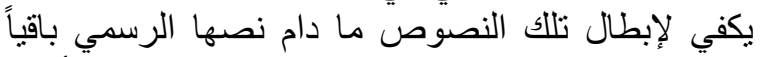

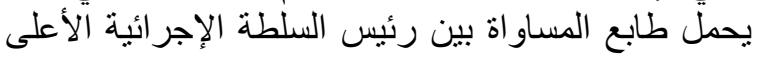

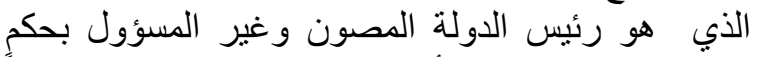

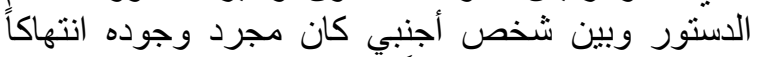

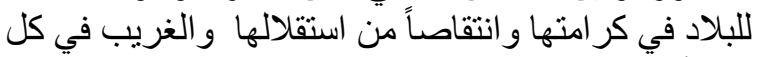

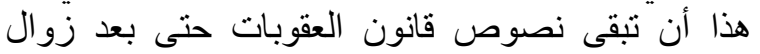

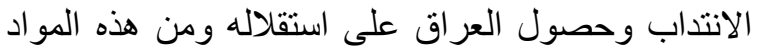

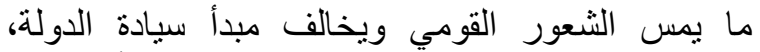
ويعارض المبادئ القانونية السليمة إذ إن إفشاء أمور إلى إلى الفي

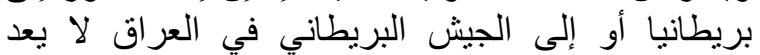

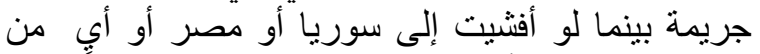

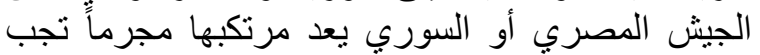

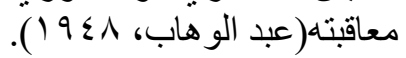

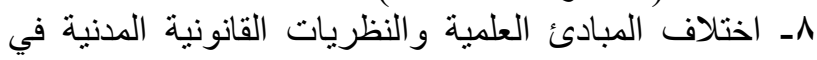

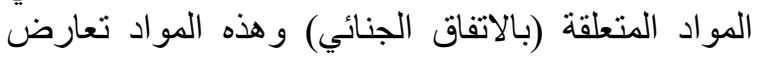

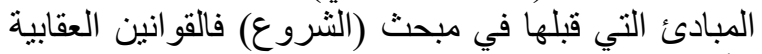

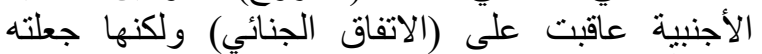

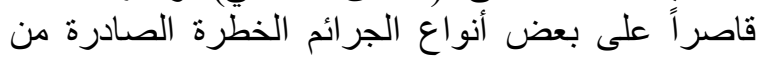

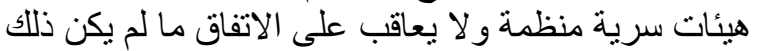

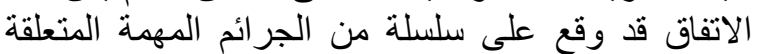

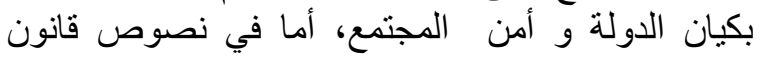

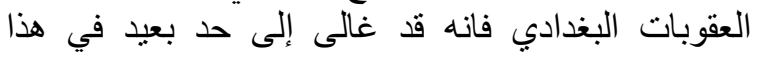

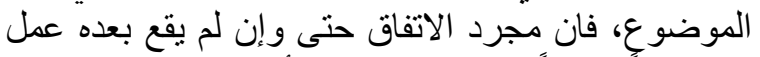

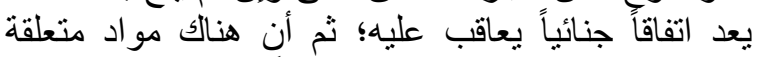

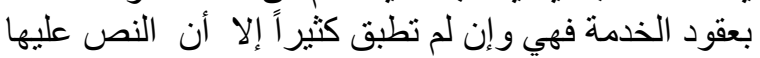

كلمة (Constable) فانه يذكر ها(كونستابل) بينما ترجمتها

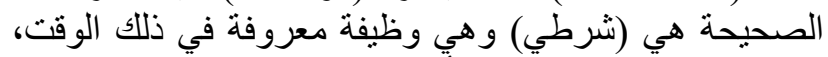

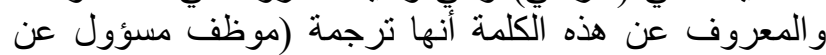

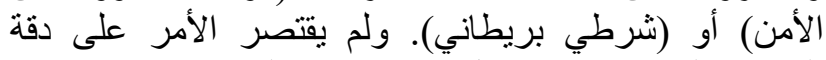

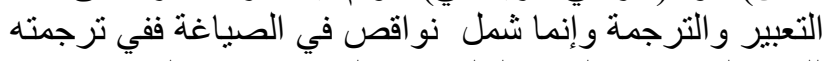

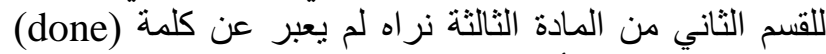

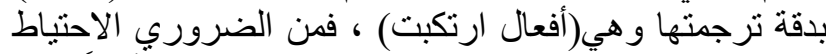

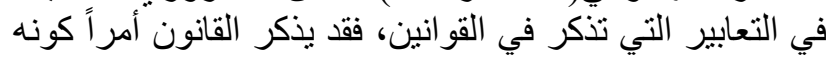

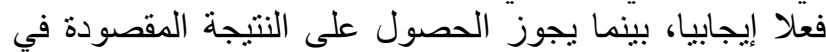

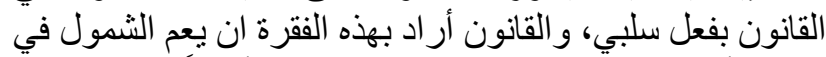

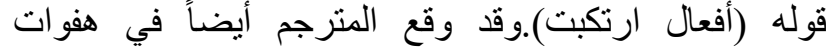

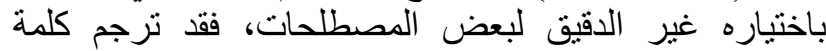
(Classes)

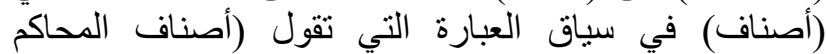
الجزائية) وكان المترجم قد ذكرهاً (تتكيل المحاكم الجزائية)

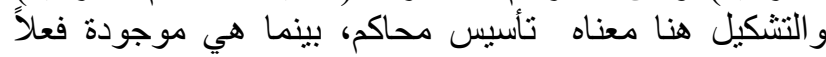

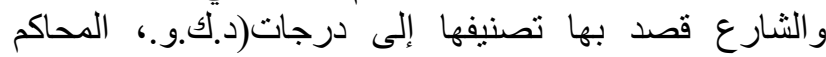

و القضايا القانونية، ـو 90 (1). وبناء على ما تقدم فقد وجهات الانتقادات العات العديدة لقانون

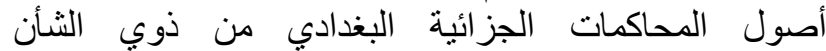
و المؤرخين ويمكن أن نوجز أهم عيوبه بما يأتي (الثناوي،

: (1)

1 - إن أول شيء يتبادر إلى الأذهان هو التسمية التي أطلقت

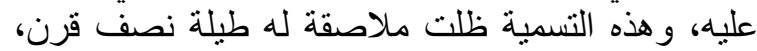

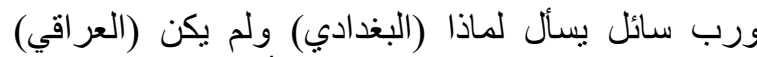

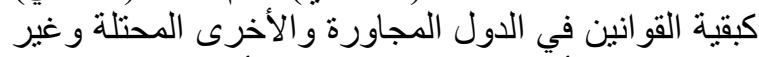

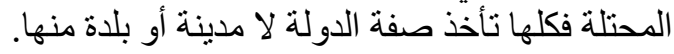

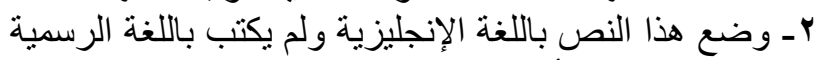

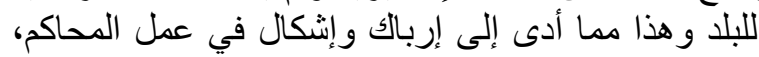

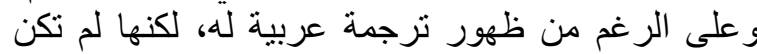

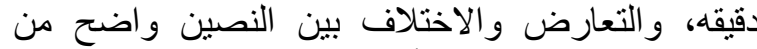

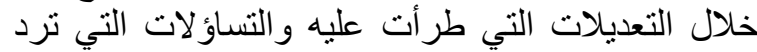

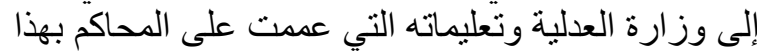

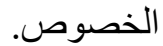
rـ احتو اء الترجمة العربية الأولى على أغلاط عربية وصياغة

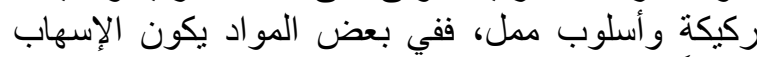

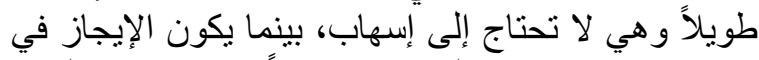

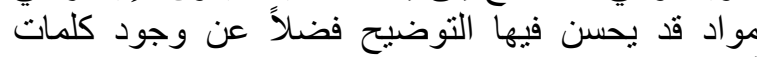

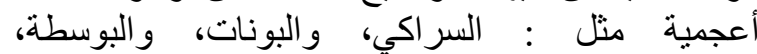
و التلغر اف، و البوليس، و الثمندورة التئ، و غير ها.

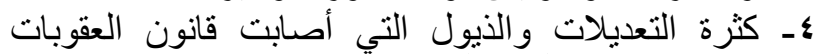

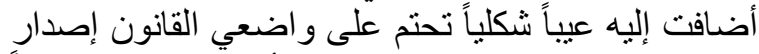

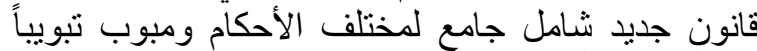
علمياً عصرياً بساير التطور الزمني الذيل الذي بلغه المجتمع،

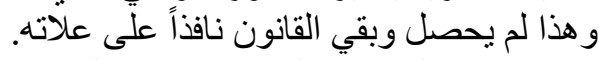

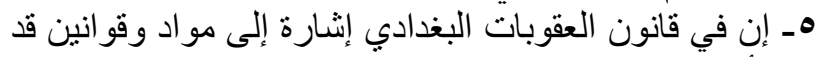

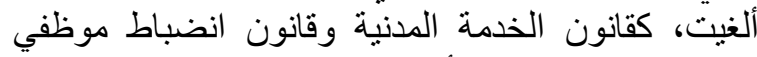

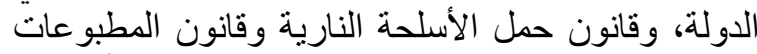

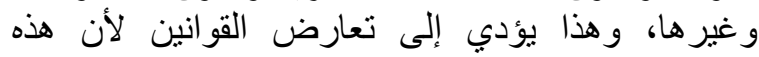


معالجته موضوع إفثاء أسرار مهنية ورد في الترجمة

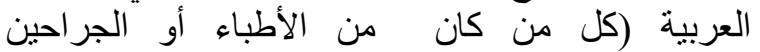

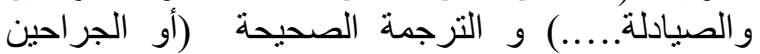

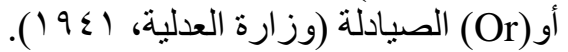

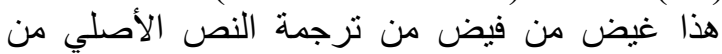

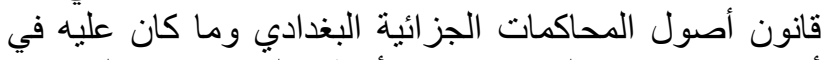

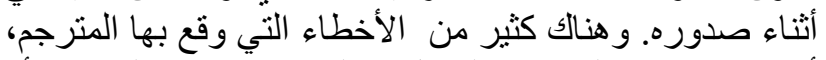

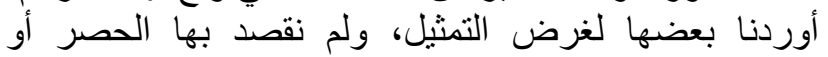

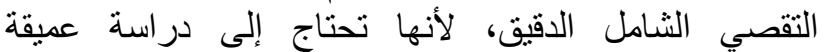

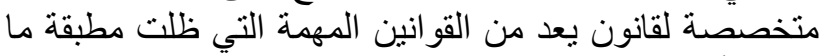
يقارب أكثر من نصف قرن في في العراق. لهذا جرت عدة محاو لات لتشريع قانون جديد للعقوبات التهات

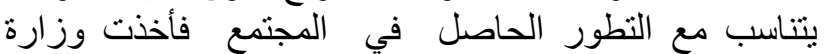

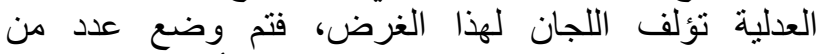

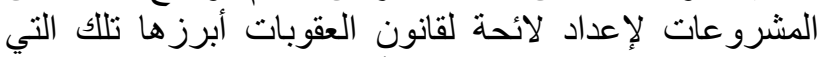

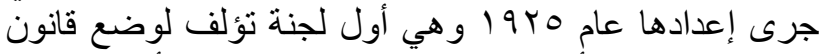

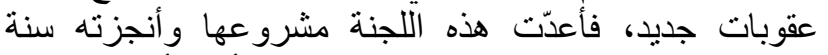

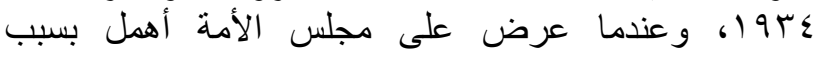

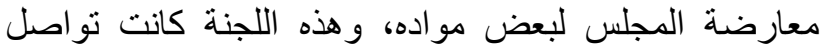

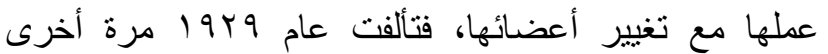

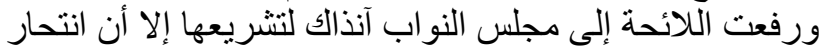

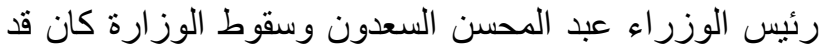

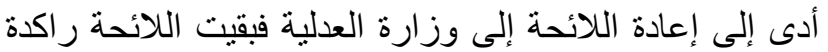

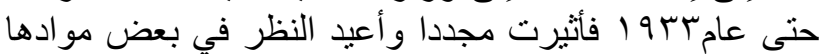

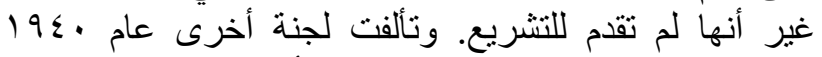

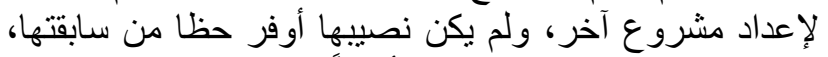

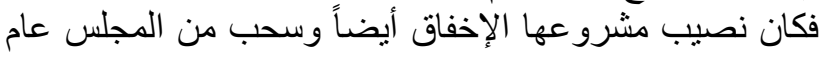

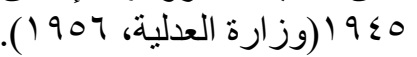
يبدو أن الأوضاع السياسية غير المناع المستقرة في البلد،

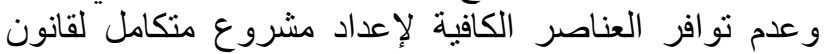

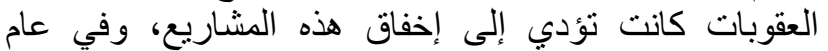

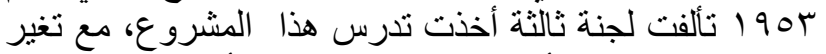

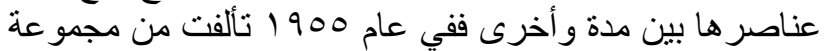

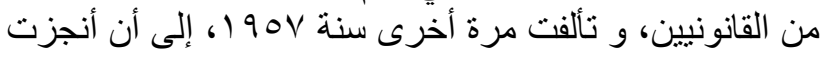

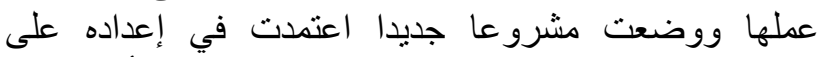

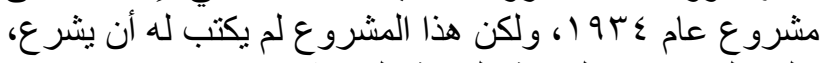

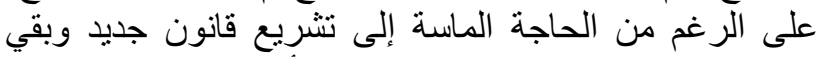

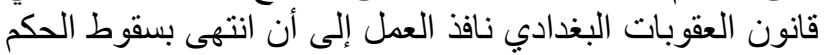

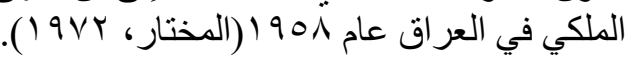

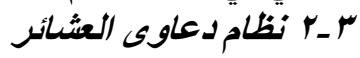

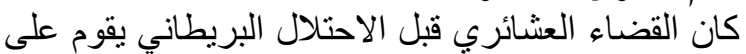

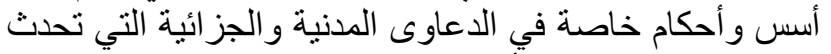

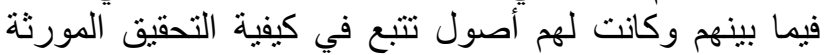

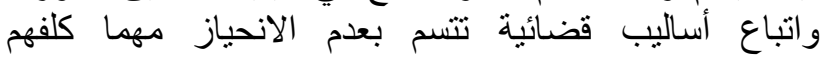
هذا (النداوي، و 1919 ()).

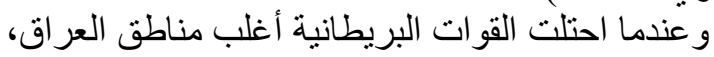

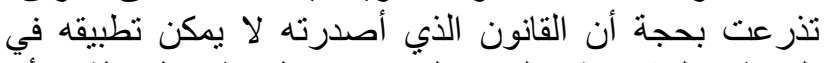

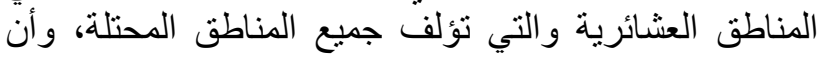

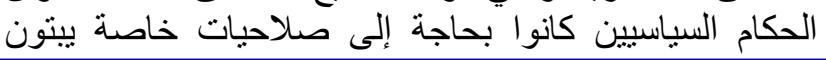

في قانون العقوبات لا يتفق مع القواعد العلمية، و وإن بعض مواد القانون غير عملية كالمادة الباحثة عن معاقية العانة

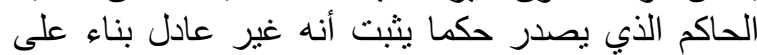

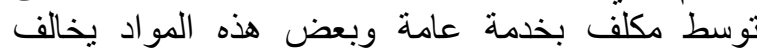

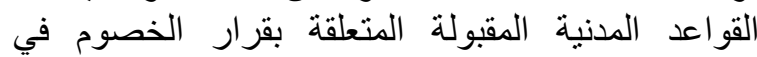

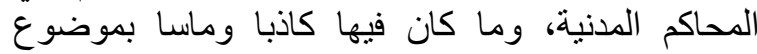

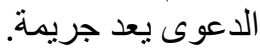

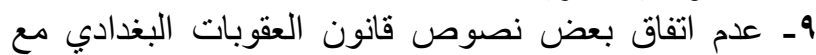

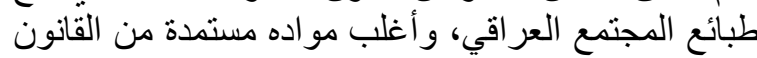

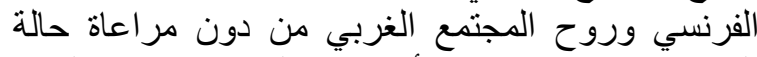

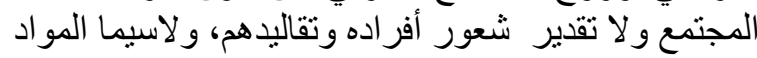

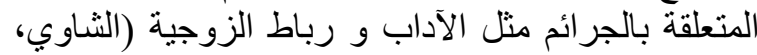

. (197

• 1 ـ عدم التمبيز بين الجريمة السياسية والجريمة العادية في

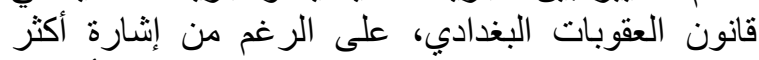

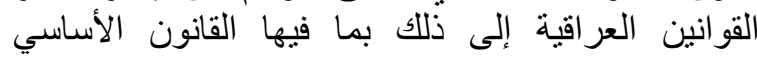

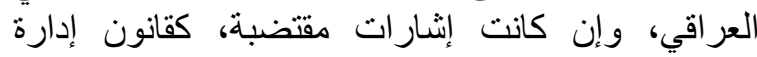

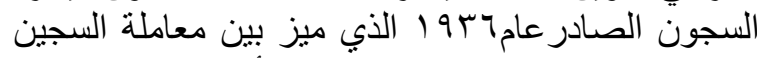

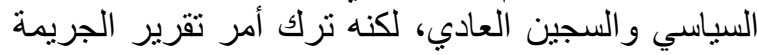

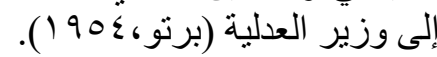

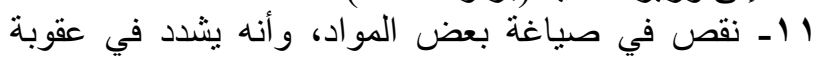

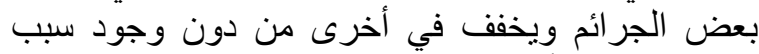

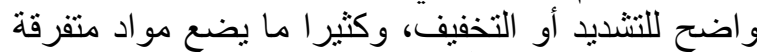

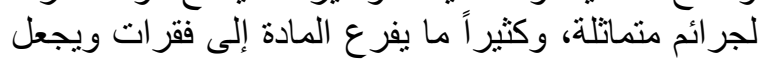
العقوبات و احدة (الثناوي، ع ع 97 1).

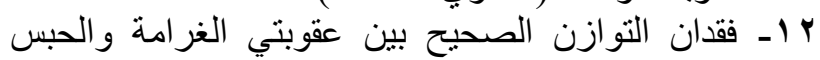

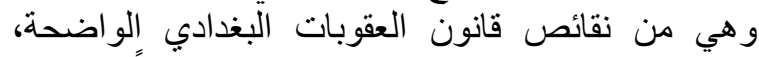

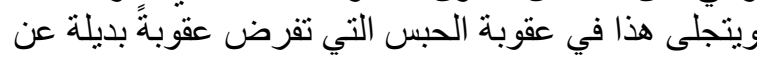

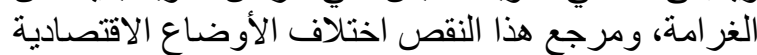

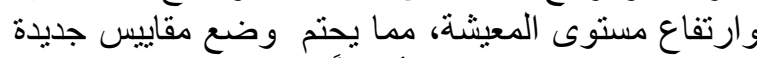

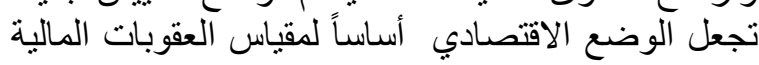

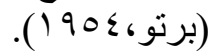

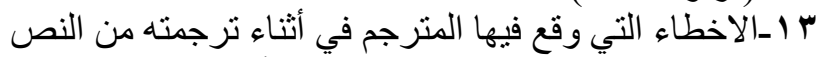

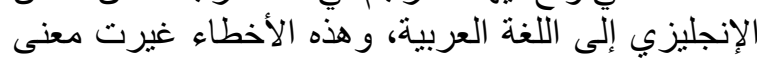

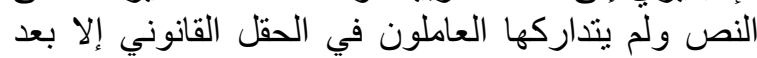

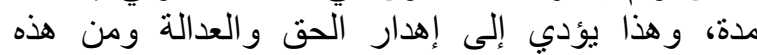

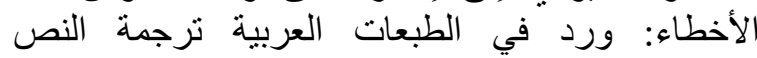

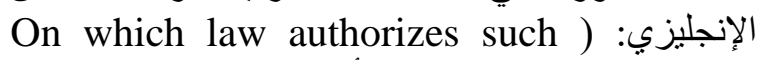
entry

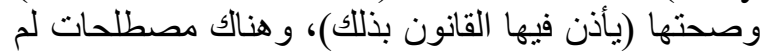

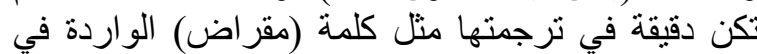

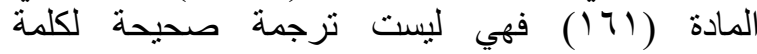
(Punch)

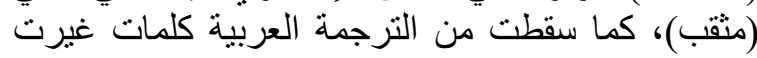

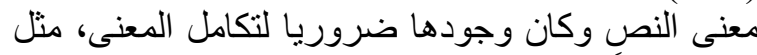

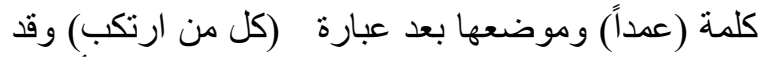
ورد النص الآتي في الطبعات العربية : (بعاقب بالأشغال

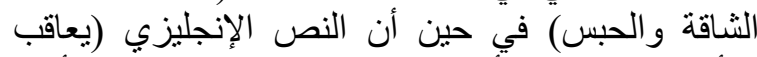

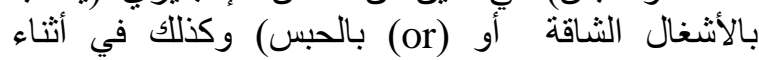


الثيوخ فأصبح الثيخ يقوم بتنفيذ ما تأمر به سلطات الاحتلال، ونال

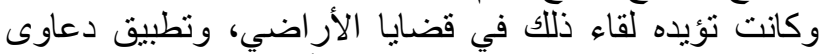

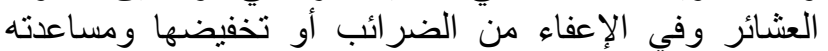
مالياً(د.ك. و.ئر وفي الإعل دعاء من العشائر ). وقد واجه هذا النظام عدة النقادات، وتعرض الن إلى إلى هجوم

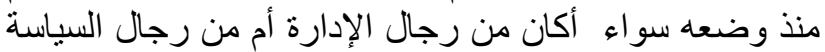

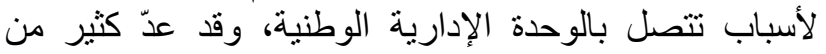

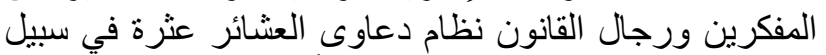

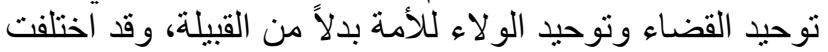

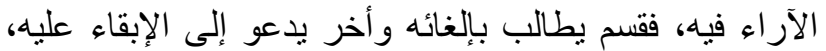

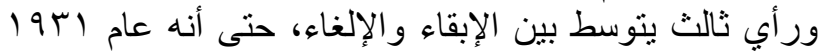

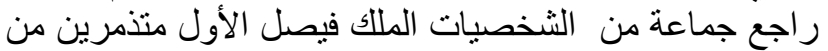

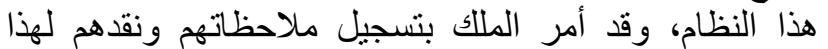

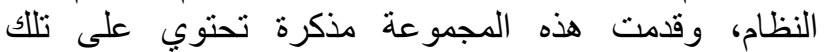

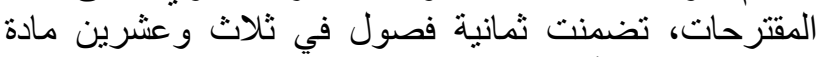

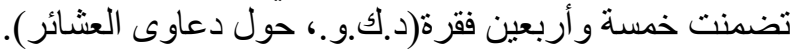

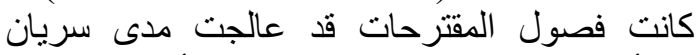

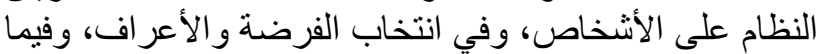

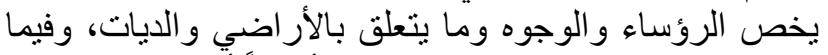

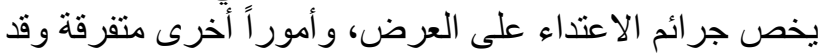

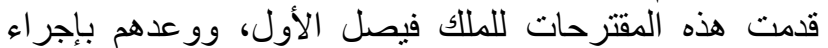

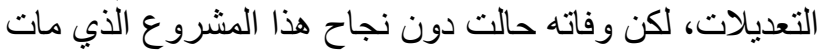

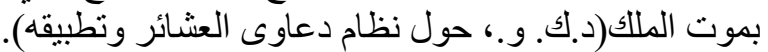

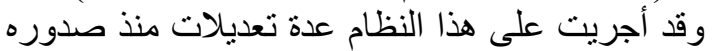

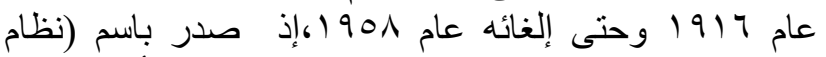

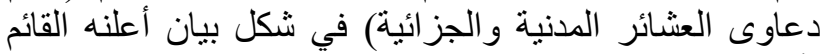

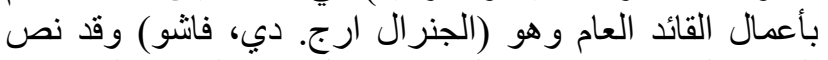

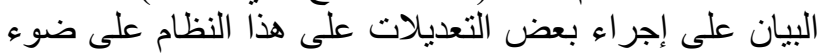

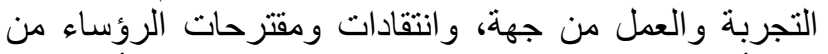

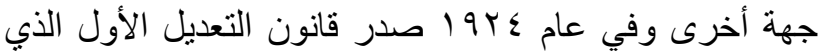

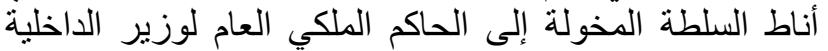

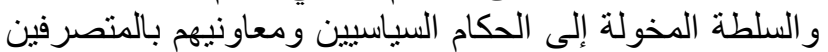

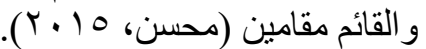

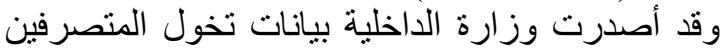

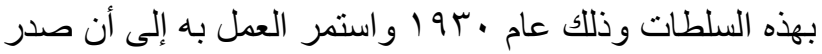

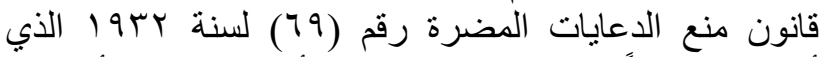

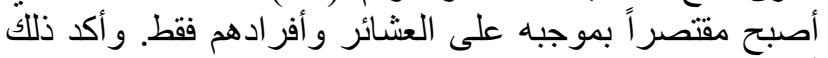

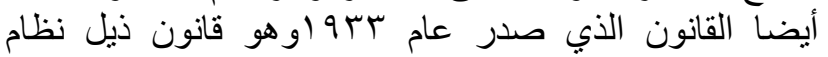

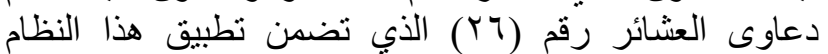

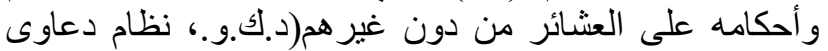

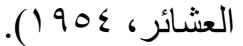

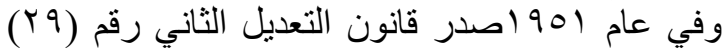

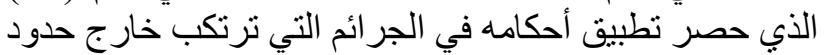

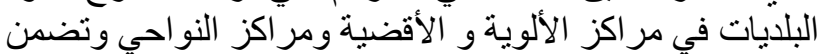

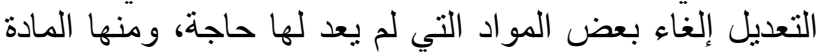

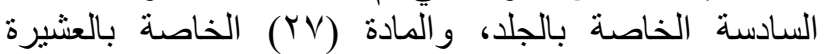

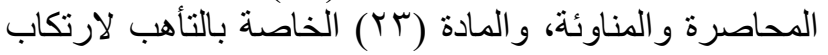

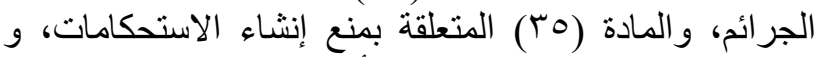

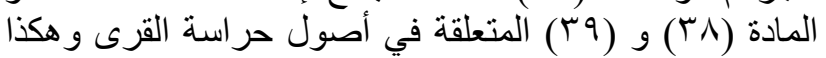

بواسطتها في القضايا الحقوقية في مناطقهم، ولتنافي هذام

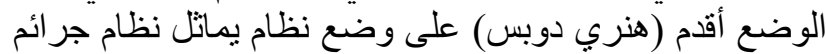

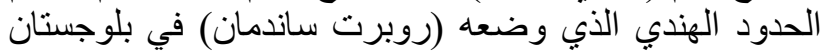
أطلق عليه اسم (نظام دعاوى العشائر المدنية والجزانية ائية) وقدان

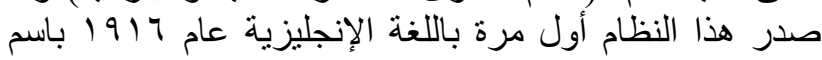
The tribal criminal and civil disputes regulations بتشكيل مجلس عشائري يحكم بموجب العناد العادات العشائرية في

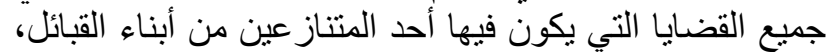

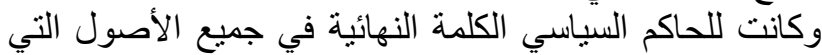
يحكم فيها، وبوسعه إعادة النظر في القضايا ويسنطيع أن يقرّ النّا

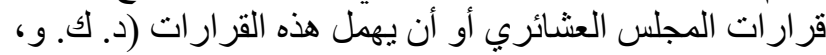

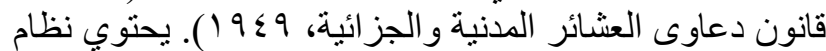

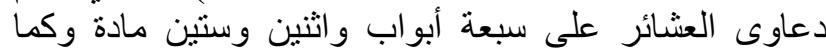

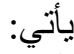
الباب الأول اشتمل على تمهيد وثلاث مو اد وضحت فيها اسم

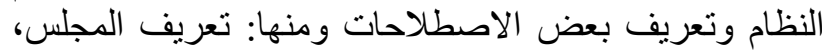

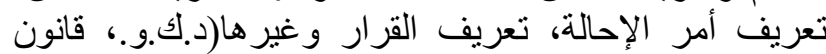

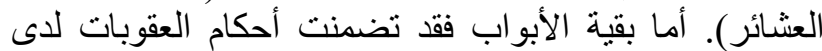

العثائر وتناول النظام موضو الأرين أساسينين: • الأول الدعاوى العشائرية وكيفية حسمها.

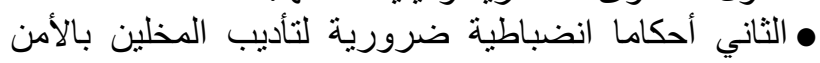
العام (د. ك. و. و.، قانون العشائر ).

ويلاحظ على مواد هذا النظام أنه لم بحتو على لمانى رسوم

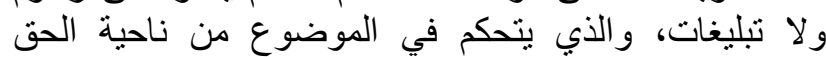

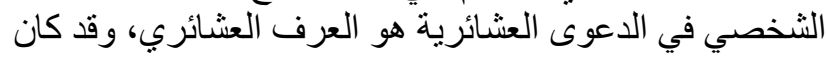

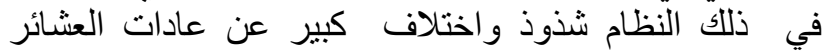

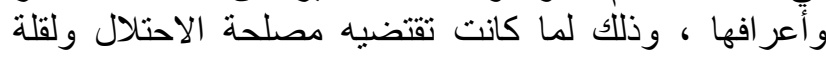

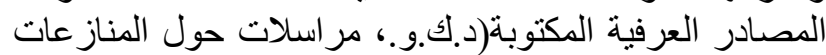

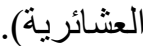
من القوانين التي نصت على الأخذ بالعرف العشائري قانون العقوبات البغدادي وقانون أصول البون الدحاكمات الجزائية

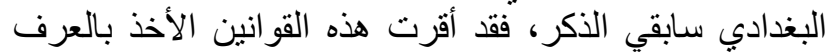

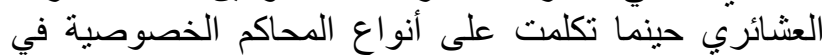

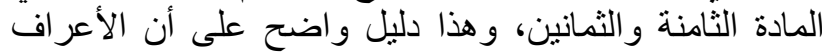

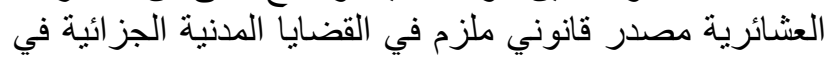
العراق (وزارة العدلية، تعليمات حول قضائل فيايا العشائر).

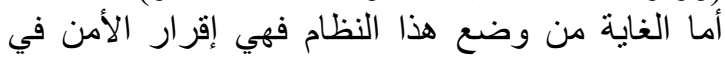

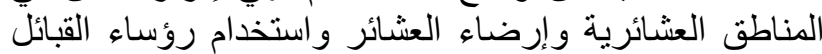

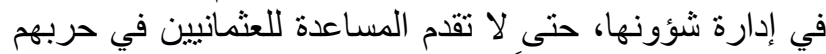

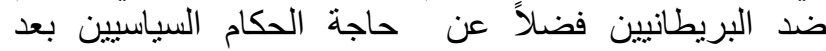

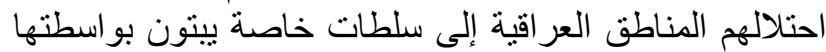
في القضايا الحقوقية والجزائية في مناطقهم، وكانت الإنية الإدارة

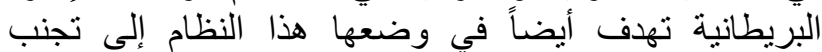

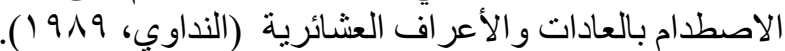

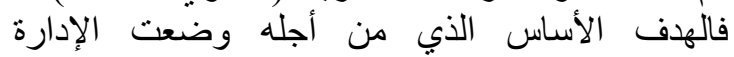

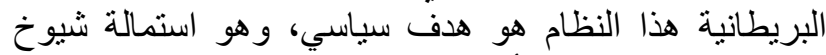

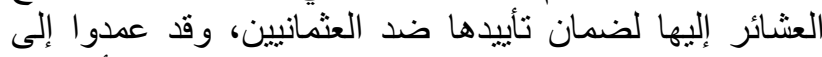
توسيع سلطات الثيوخ وحصر السلطة في يد عدائند وند أقل من 


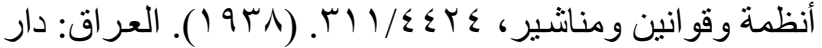

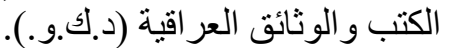

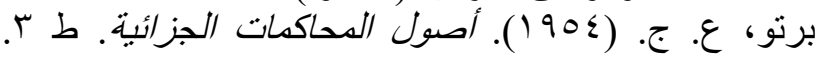
بغداد: مطبعة العاني.

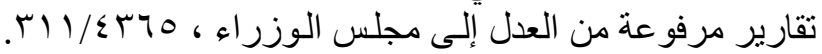

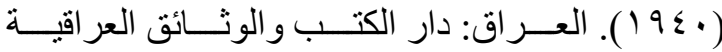

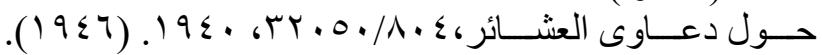
العر اق: دار الكتب والوثائق العر اقية (د.ك.أك.و.).

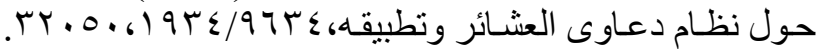

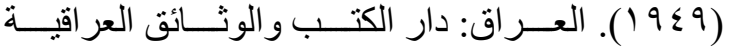

خدوري، م. (9 (9 1) ). نظام الحكم في العراق. ترجمة فيصل

نجم الدين الاطرقجي. بغداد: مطبعة الرابطة.

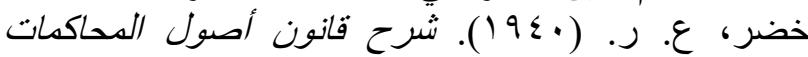

الجزائية البغدادي. ط بـ بـ بغداد: مطبعة السريان.

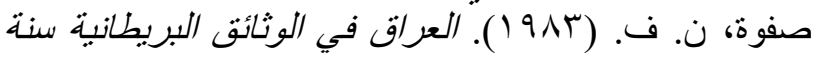

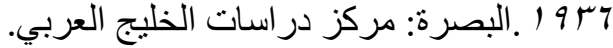

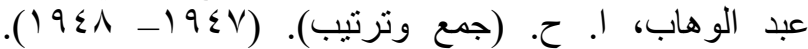

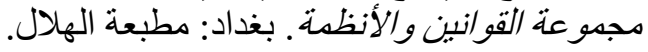

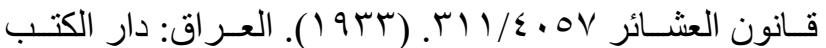

$$
\text { و الونائق العر اقية (د.ك.ك.و.). }
$$

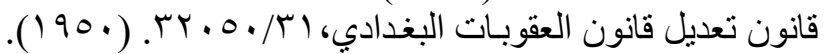

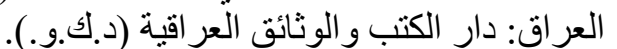

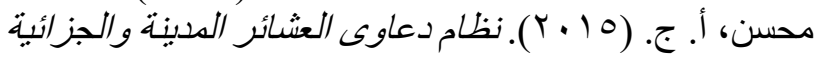

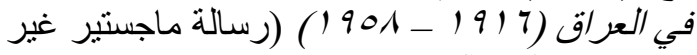

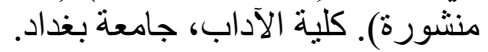

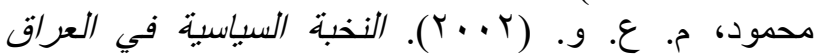
.

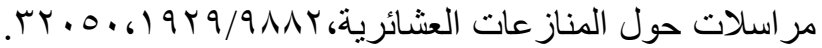

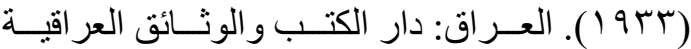

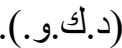

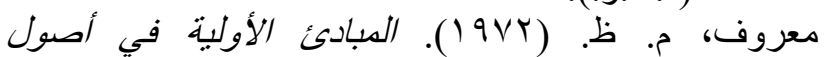

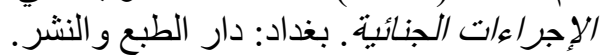

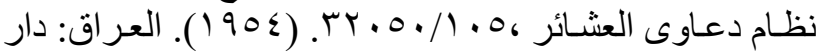

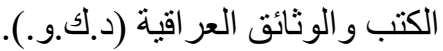

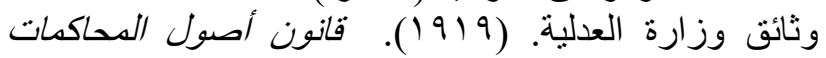

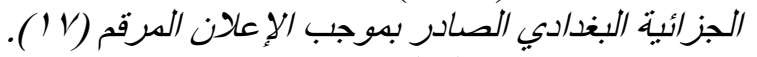
بغداد: مطبعة وز ارة العدلية.

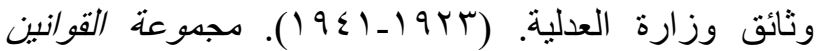
والأنظمة بغدادة العذانة مطبعة وز ارة العدلية.

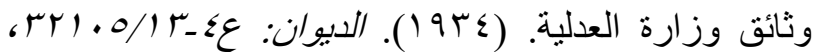

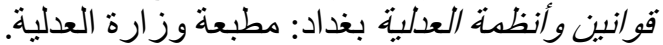

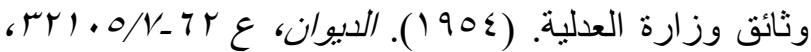

قانون العقوبات. بغداد: مطبعة وز ارة العارة العدلية.

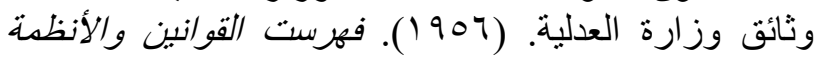
والبيانات المنشورة في العراق. بغداد: مطبعة وزارة العنة

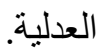

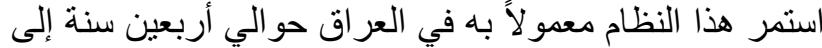

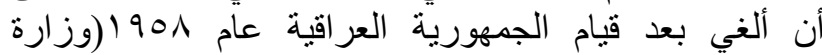

العدلية، الغي (1907). ع ـ الخاتمة والنة، ولائج

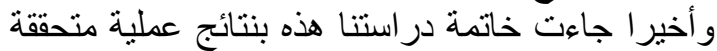

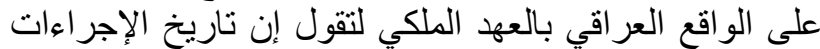

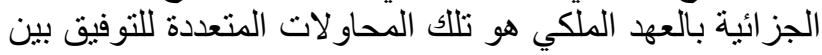

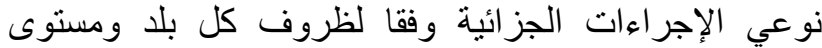

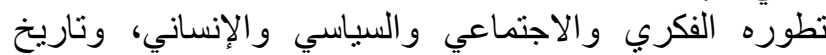

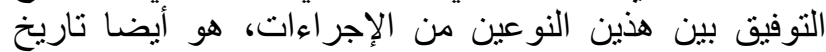

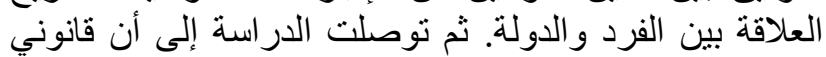

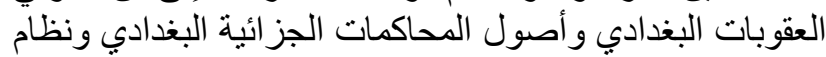

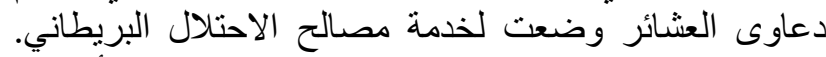

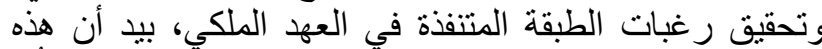

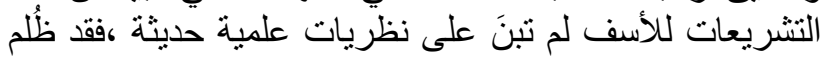

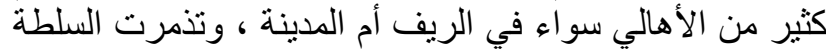
القضائية و العاملين في الدجال القانوني في أنثاء تنفيذ أحكام هذا القانون . الفنان

\section{المصادر والمراجع (1) - (اجع}

الأورفلي، م. (749 1). محاضرات في في القضاء العراقي.

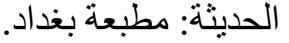

البزاز، ع. ر. (97V (19). العراق من الاحتلادل حتى الاستقلال.

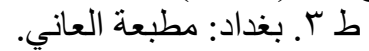

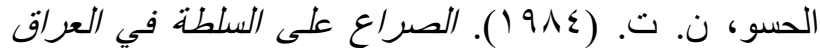
الملكي. بغداد: مطبعة الكندي.

الثناوي، س. (r I I ). أصول التحقيق الإجرامي. بغداد: دار الحرية للطباعة.

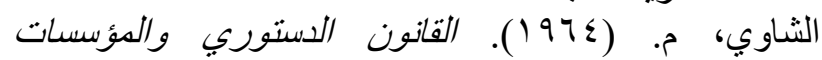

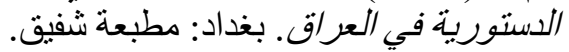

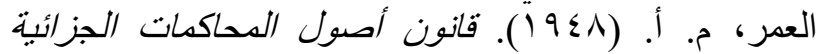

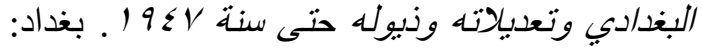
مطبعة الكاني.

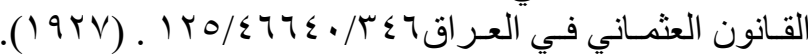
العراق: دار الكتب و الوثائق العر اقية (د.ك. أكو.).).

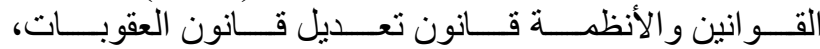

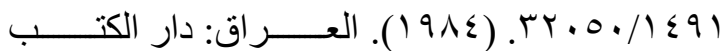
و الوثائق العر اقية (د.ك. (ك.و.).

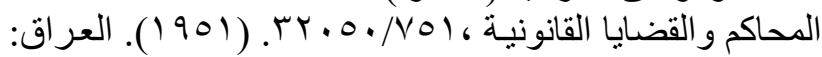

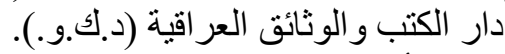

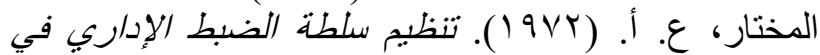
العراق (رسالة ماجستير غير منشورة). كلية القانون،

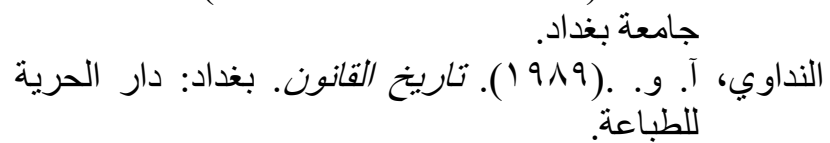

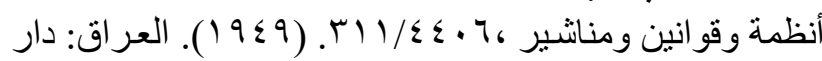
الكتب و الوثائق العر اقية (د.ك.و.و.). 
issued under proclamation No. 17. Baghdad: Justice Ministry Press.

Documents of the Ministry of Justice. (1934). Al-Diwan, No. 4-13 / 32105: Laws and regulations of justice. Baghdad: Justice Ministry Press.

Documents of the Ministry of Justice. (1954). Al-Diwan, pp. 62-7/32105: The penal code. Baghdad: Justice Ministry Press.

Documents of the Ministry of Justice. (1956). Index of laws, regulations and statements published in Iraq. Baghdad: Justice Ministry Press.

Iraqi Library and Archives. (1927). Ottoman Law in Iraq, 346/46640/125. Iraq: (K.D.W).

Khader, A. R. (1940). Explanation of alBaghdadi's criminal procedure code. $2^{\text {nd }}$ Edition. Baghdad: Al-Syrian Publishing House.

Khaduri, M. (1949). The system of government in Iraq. (Translated by Faisal Najm AlDin Al-Atarqji). Baghdad: Al-Rabita Publishing House.

Laws and Regulations: Penal Code Amendment Law 1948/32050. (1491). Iraq: (K.D.W).

Maarouf, M.A. (1972). Elementary principles of criminal procedure. Baghdad: Publishing House.

Mahmoud, M.A (2002). The political elite in Iraq 1920-1958. Baghdad: Al-Hikma House for Publication.

Ministry of Justice documents. (1923-1941). Laws and Regulations collection. Baghdad: Justice Ministry Press.

Ministry of Justice. (1943). Tribal court of cassation No. 295/320583: Instructions on tribal issues. Baghdad: Justice Ministry Press.

Mohsen, C. (2015). The System of civilian and penal clans claims in Iraq (19161958)(An Unpublished Master Thesis). College of Arts, University of Baghdad.

On Clan Claims 804/32050. (1940-1946). Iraq: (K.D.W).

On the Clan Claims System and Its Implementation 32050 9634. (1934-1949). Iraq: (K.D.W).

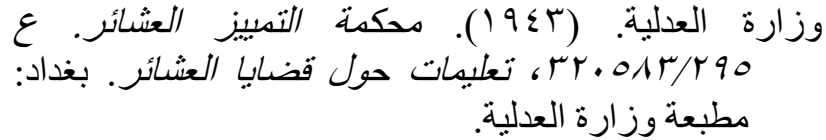

\section{Translated References}

Abdel-Wahab, A. H. (collection and arrangement). (1947-1948). Laws and regulations collection. Baghdad: Al-Hilal Publishing House.

Al-Baghdadi Penal Code Amending Law 31/32050. (1950). Iraq: (K.D.W).

Al-Bazzaz, A.R. (1967). Iraq from occupation until independence. 3rd Edition. Baghdad: Al-Ani Publishing House.

Al-Haso, N.T. (1984). The struggle for power in royal Iraq. Baghdad: Al-Kindi Press.

Al-Mukhtar, A. A. (1972). Organization of the administrative control authority in Iraq (An Unpublished Master Thesis). College of Law, Baghdad University.

Al-Nadaawi, A.W. (1989). History of law. Baghdad:Al-Hurriyah Publishing House.

Al-Orfali, M. (1936). Lectures in the Iraqi judiciary. Haditha: Baghdad Publishing House.

Al-Shawi, M. (1964). Constitutional law and constitutional institutions in Iraq. Baghdad:Shafiq Publishing House,

Al-Shawi, S. (1972). The origins of the criminal investigation. Baghdad: Al-Hurriya House for Printing.

Al-Umer, M.A. (1948). Al-Baghdadi's criminal procedure law, its amendments and appendices until 1947. Baghdad: AlAni Publishing House.

Barto, A.J. (1954). Fundamentals of criminal trials. $3^{\text {rd }}$ Edition. Baghdad: Al-Ani Publishing House.

Correspondence on Clan Disputes 9882/32050. (1929-1933). Iraq: (K.D.W).

Courts and Legal Cases 32050 751. (1951). Iraq: (K.D.W).

Documents of the Ministry of Justice. (1919). Al-Baghdadi criminal procedure law 
Regulations, Laws, and Pamphlets 4406/311. (1949). Iraq: (K.D.W).

Regulations, Laws, and Pamphlets 4424/311. (1938). Iraq: (K.D.W).

Reports Submitted by Justice to the Council of Ministers 4365/311. (1940). Iraq: (K.D.W).

Safwa, N.F. (1983). Iraq in British documents in (1936). Basra: Center for Arab Gulf Studies.

The Clan Claims System, 105/32050. (1954). Iraq: (K.D.W).

The Clans Law. (1933). 4057/311. Iraq: (K.D.W). 